\title{
Die Familienthematik in der (TV-)Serie: Historische Entwicklung, Bedeutung und Ausblick
}

Die Geschichte der US-amerikanischen Fernsehserie ist eng mit der Familienthematik verknüpft. ${ }^{1}$ Vor allem die sogenannten „Family-Sitcoms“, aber auch Familienserien anderer Art bilden das zentrale Element der Serienlandschaft. ${ }^{2}$ Dementsprechend werde ich wiederholt exemplarisch auf Sitcoms Bezug nehmen. Der immerwährende Erfolg von Familiendarstellungen beruht darauf, dass Familien ebenso ein großes „Identifikationspotenzial wie eine große Bandbreite an Möglichkeiten zur Handlungsvariation" bieten (Kelsch 2019: 25, vgl. auch Kutulas 2016: 17). Wie in Literatur und Film gibt es also auch in der Serie eine große Varianz bei der Darstellung von Familien. Dies bedeutet allerdings nicht,

\footnotetext{
${ }^{1}$ Aufgrund der großen inhaltlichen und thematischen Nähe ist das folgende Kapitel 2. eng an meine Masterarbeit „Familien-Modelle in der populärkulturellen US-amerikanischen Zeichentricksitcom" angelehnt (vgl. Kelsch 2019: 26-35), wurde aber erweitert und überarbeitet. Alle direkten und indirekten Zitate sind als solche gekennzeichnet. Die Kapitelüberschriften sind an den Überschriften eines entsprechenden Überblicks in der Masterarbeit orientiert.

${ }^{2}$ Vor allem bezüglich der Entwicklung der Familiendarstellung kann die Sitcom, die als Format der Massen- und Populärkultur lange Zeit die dominante Gattung im Bereich der Serie war, über einen gewissen Zeitraum als beispielhaft für die Gesamtentwicklung gelten. Sitcoms lassen sich in die zwei dominanten Genres der ,Workplace-Sitcom“ und der „Family/Domestic-Sitcom“" (vgl. Baker 2003: 27 ff., vgl. auch Nilsen/Nilsen 2000: 278) unterteilen. Über die Genrekonzeption der Sitcom werden hier also die zwei zentralen Lebensbereiche der meisten Menschen, Arbeit und Familie, und damit auch Öffentlichkeit und Privatheit in Opposition gestellt (vgl. Kelsch 2019: 24). Aufgrund der politischen und gesellschaftlichen Dogmatisierung der Familie in den USA ist es dabei nicht verwunderlich, dass Family-Sitcoms generell vorherrschen (vgl. Baker 2003: 47). Zwischen 1950 und 1995 wurden insgesamt 630 Serien auf den großen kommerziellen US-amerikanischen Fernsehsendern (ABC, CBS, FOX, NBC) ausgestrahlt, die eine Familie fokussierten. Davon waren $72 \%$ Sitcoms und ca. $28 \%$ Drama-Serien (vgl. Robinson/Skill 2001: 146). Dies zeigt nicht nur eine starke Dominanz der Sitcom, sondern die Bedeutung der Familie in der Serie insgesamt.
} 
dass bestimmte Rollen- und Handlungsmuster ebenso wie bestimmte Kategorien von Normen und Werten nicht wiederholt wiederkehren.

Zwar handelt es sich bei der Entwicklung der Familiendarstellung in der Serie um einen kontinuierlichen Prozess, dessen Verlauf nicht absolut klar zu unterteilen ist, dennoch lassen sich anhand der Jahrzehnte bestimmte Tendenzen feststellen, die meist in Interdependenz mit den jeweiligen politischen und gesellschaftlichen Gegebenheiten stehen und eine ungefähre Einteilung in bestimmte Abschnitte ermöglichen. Diese Einteilung gilt nicht absolut, sondern soll helfen, die dominanten Entwicklungen innerhalb eines gewissen Zeitraums zu beschreiben. Einhergehend mit der Auswahl meines späteren Analysekorpus, beschränke ich mich darauf, Entwicklungen in US-amerikanischen Serien nachzuvollziehen. Dem Überblick über die historische Entwicklung geht eine Reflexion der gesellschaftlichen Rolle der Familienserie sowie der Familienthematik in Serien voraus. $^{3}$ Nach einem Resümee dieser Entwicklungen bildet eine eingehende Untersuchung der Potenziale der Video-on-Demand-Anbieter im Vergleich zum konventionellen Fernsehen, auch abseits der Familienthematik, den Abschluss.

\subsection{Die Familienthematik in der Serie: Gesellschaftliche Relevanz und Modellierung}

The fictional family on television, in its many forms, has become one of our most enduring benchmarks for making both metric and qualitative assessments of how the American family is doing in the real world. For many in the arena of public policy, the debate frequently points to television as primary source for what is good or bad about the family institution. (Robinson/Skill 2001: 139)

Die integrale gesellschaftliche Bedeutung der Familie wird stets aufs Neue von US-amerikanischen Politikern betont. Sie gilt als ,cornerstone of society“ (Lyndon B. Johnson) oder wird ,at the center of our society“ (Ronald Reagan) verortet (vgl. Heinemann 2012: 7). Ein beliebter Indikator für die realen Familienverhältnisse und den Zustand familiärer Werte in den USA ist dabei das Leben fiktionaler Fernseh-Familien (vgl. Bryant et al. 2001: 247). Gesamtgesellschaftlich wird - wie Andre Dechert in Bezug auf Sitcoms feststellt - den Formaten ,eine potenzielle Wirkmächtigkeit“ zugeschrieben (Dechert 2018: 203) und mediale

\footnotetext{
${ }^{3} \mathrm{Zu}$ einer umfassenden Untersuchung zur Familienserie der späten 1970er bis frühen 1990er Jahre und dem zugrunde liegenden Wertemodell möchte ich auf Das Wertesystem der Familienserien im Fernsehen von Jan-Oliver Decker, Hans Krah und Marianne Wünsch verweisen (vgl. Decker et al. 1996). Die Ergebnisse der Autoren sind auch heute weiterhin gültig und werden von mir im Folgenden wiederholt herangezogen werden.
} 
Debatten um Familien in Sitcoms als ,bedeutende Aushandlungsprozesse von Familienwerten“"verstanden (vgl. Dechert 2018: 205). Hinter eher progressiven oder kritischen Formaten wird dabei von konservativer Seite nicht selten ein Werteverfall vermutet, wie etwa im Falle des Präsidenten George Bush Sr., der 1992 ,a nation closer to The Waltons than The Simpsons“" forderte (vgl. Henry 2012: 6, vgl. auch Bryant et al. 2001: 247).

Wissenschaftliche Untersuchungen bezüglich der Frage, inwieweit fiktionale Weltmodelle bzw. mediale Familienmodelle Aussagekraft über reale Zustände besitzen, gehen allgemein davon aus, dass Fiktion und Wirklichkeit alles andere als deckungsgleich sind. Dies tut der Popularität dieser Vergleiche in öffentlichen Debatten indes keinen Abbruch (vgl. Robinson/Skill 2001: 152). Einer Untersuchung von James D. Robinson und Thomas Skill zufolge ist das Fernsehen höchstens ein ,close follower“ realer Entwicklungen. „Over all, the data suggest that television is far more likely to reinforce traditional models of family than to promote nonconventional configurations" (Robinson/Skill 2001: 140). ${ }^{4}$ Eher spiegelt das Fernsehen bereits Geschehenes wieder, als selbst „Trendsetter“ zu sein (vgl. Heintz-Knowles 2001: 198). Ebenso wenig lässt sich belegen, dass Familienserien dazu tendieren, psychologisch besonders, ungesunde 'Familien darzustellen und diese Darstellungen, durch Nachahmung negativer Rollenmuster, in dysfunktionalen Familien in der Realität Wurzeln schlagen (vgl. Bryant et al. 2001: 248). Hickethier stellt fest, dass sich die Weltmodelle von Serien allgemein der Realität anpassen, gesellschaftliche Entwicklungen, durch deren mediale Verbreitung, gefestigt werden und diese nicht anstoßen:

Die Geschichte der Serien kann unter diesem Aspekt einer immer wieder neuen Diskussion über Verhaltensweisen gesehen werden, wobei sich die in den Serien

\footnotetext{
${ }^{4}$ In ihrem Aufsatz Five Decades of Families on Television: From the 1950 s Through the 1990 s gleichen Robinson und Skill die Familienverhältnisse im Fernsehen mit realen USFamilienverhältnissen von den 1950ern bis in die 1990er Jahre ab. Die Ergebnisse zeigen deutliche Unterschiede. Als Beispiel zu den 1950er Jahren: Während in 57,8 \% der Serien ein Elternpaar ,head of house“ war, 17,2 \% der Serien alleinerziehende Väter und 14,1\% alleinerziehende Mütter zeigten, waren - laut der Volkszählung von 1960 - nur 1,1 \% der Väter und 8,0 \% der Mütter alleinerziehend. 87,8 \% der Familienoberhäupter waren indes Elternpaare. Die Entwicklung der kommenden Jahrzehnte zeigt, dass Fernsehfamilien der Realität eher folgen als sie vorwegnehmen: Nimmt also beispielsweise die Zahl alleinerziehender Mütter in der Realität zu, nimmt auch die Zahl alleinerziehender Mütter in Serien zu (zu allen Angaben vgl. Robinson/Skill 2001: 154). Diese Aussage ist jedoch mit Vorsicht zu genießen, da sie nur partiell durch die Datenlage bestätigt wird. Vor allem lässt sich feststellen, dass die Entwicklung der Fernsehfamilie eher lose an die Realität gekoppelt ist. Obwohl sich die fiktionale Familie ebenfalls wandelt, scheinen Serien mehr darauf bedacht, mit diversen Familienmodellen zu experimentieren (vgl. Robinson/Skill 2001: 161).
} 
thematisierten Handlungen im Laufe der Jahrzehnte verändern, der Zeit ,anpassen“, d.h. die jeweils im gesellschaftlichen Kontext notwendige Anpassung von Verhaltensweisen an gesellschaftliche veränderte Lebensverhältnisse, Normen und Werte über das Seriengeschehen zur Diskussion stellen. Die Serien können deshalb - wie das Fernsehen insgesamt - als Teil der gesellschaftlichen Modernisierungsprozesse verstanden werden: das Fernsehen als Ort, an dem die für die Modernisierung notwendigen Verhaltensmodellierungen angeboten und verbreitet werden. (Hickethier 1994: 70)

Ungeachtet der Diskrepanz zwischen medialer Darstellung und Realität lässt sich indes nicht leugnen, dass mediale Modelle von Wirklichkeit die Wahrnehmung der Realität beeinflussen (vgl. Bryant et al. 2001: 248). Was Rezipierende in Serien sehen, mag ihr Bild der Realität ebenso formen wie die realen Umstände.

Inspired by Michel Foulcault, who saw government as dispersed through-out culture and everyday life, I look at sitcoms as a cultural technology, part of a broader governing rationality where the conduct of families is shaped in part through their engagement with media. (Leppert 2019: 4)

Family-Sitcoms und - so kann man ergänzen - mediale Abbilder von Familien im Allgemeinen bilden Schablonen, mit denen die Rezipierenden ihre Lebensrealität abgleichen. Wird ein bestimmtes Ideal von Familie medial geprägt und werden bestimmte Verhaltensweisen als optimal bzw. ideal gesetzt, kann dies beispielsweise zu einer Wahrnehmung der eigenen Realität als defizient führen, falls sie diesen Modellen nicht entspricht. ${ }^{5}$

Ist dies wohl nicht in jedem Fall die direkte Intention der Medienschaffenden, vermitteln Familienserien stets einen bestimmten Kanon an Werten, häufig implizit:

Das Wertesystem der Familienserien läßt sich in den einzelnen Serien häufig nur ex negativo aus den dargestellten Abweichungen und deren Sanktionen erstellen. Sanktionen reichen dabei auf der Ebene der Figuren von nicht erfüllten und als sinnlos bewerteten Lebensläufen bis zur Eliminierung bestimmter Figuren, sei es durch Unfall, Wahnsinn, Gefängnis oder Tod. Familienserien führen deshalb in ihrer jeweiligen

\footnotetext{
${ }^{5}$ Thomas Skill schreibt dem Selbstvergleich mit Serien wie The Waltons sogar destruktive Auswirkungen $\mathrm{zu}$ : ,My sense is that the idealized family image is potentially the most destructive and that, for example, the expectations of viewers for their own families to be like The Waltons is an unattainable goal. The ideal is never real, and the failure of one's own family to measure up to the ideal television family may compound the problems and pressures felt by the average family“ (vgl. Skill 1983: 146). Diese ,Gefahr“ ist vergleichbar mit dem gesellschaftlichen Druck, der z. B. durch medial verbreitete Ideale von Schönheit bzw. von , angebrachtem ‘ männlichen und weiblichen Verhalten erzeugt wird.
} 
Erzählgegenwart Reaktionen auf Normverstöße vor, die in der nahen und entfernten Vergangenheit der erzählten Zeit der Serien liegen. (Decker et al. 1996: 21)

Anhand des Handelns der Figuren und den Konsequenzen, die sich für die Figuren aus diesem Handeln ergeben, lässt sich auf bestimmte Wertungen innerhalb des Weltmodells schließen. ,Böse“ oder in der Logik des Weltentwurfes abzulehnende Charaktere werden somit in der Regel nicht als Familienmenschen dargestellt (vgl. Skill 1983: 141). So wird in der Serie Grace and Frankie Brianna, die Tochter der Protagonistin Grace, allgemein als erfolgreiche und emanzipierte Frau gezeigt, die ein Unternehmen leitet. Darin ähnelt sie zwar ihrer Mutter, doch im Gegensatz zu dieser ist sie weder verheiratet noch befindet sie sich in einer Partnerschaft. Prinzipiell gibt sie sich kühl und distanziert von der Familie. ${ }^{6}$ Letztlich wird sie aber immer wieder von ihrer persönlichen Einsamkeit und den Schuldgefühlen gegenüber ihrer Familie geplagt, so dass sie einen Teil ihrer Selbstständigkeit opfert, um eine Paarbeziehung einzugehen. ${ }^{7}$ Durch diese Paarbeziehung wird sie emotional zugänglich und ,berührbar' und somit ihrem Status als tendenziell unsympathischer Charakter enthoben. In diesem Falle wird durch das Handeln der Figur Brianna und dessen (hier vor allem psychische) Konsequenzen die Bedeutung von Familie und Paarbindung als Raum positiver emotionaler Bestätigung und Geborgenheit demonstriert. ${ }^{8}$

Die Handlungsverläufe einer Serie ermöglichen einen Schluss auf bestimmte Wertemodelle, auch da die zentralen Handlungselemente einer Serie meist Verstöße gegen eine bestimmte Norm bzw. Ordnung darstellen, die sich vom Alltag der Figuren abheben. Dieser Alltag ,wird von den Rezipienten als nicht erzählenswert bewertet, woraus folgt, daß überwiegend die Abweichungen als das ,für die Rezipienten Interessante " in den Serien fokussiert werden" (Decker et al. 1996: 45). Ganz im Sinne des Konsistenzprinzips (vgl. 1.1) ist die Handlung eine Abweichung von einer bestehenden Ordnung bzw. wird durch diese bedingt und muss getilgt werden.

\footnotetext{
${ }^{6}$ So kommuniziert sie mit ihrer Mutter nur über Textnachrichten (vgl. Grace and Frankie I/2: 13:00), vernachlässigt also die Familie und entrümpelt - ohne besondere Sentimentalität - ihr altes Kinderzimmer (vgl. Grace and Frankie I/8: 14:00).

${ }^{7}$ Beispielsweise wird sie beim Ausmisten der Wohnung sentimental, als sie ein altes Kuscheltier wiederfindet (vgl. Grace and Frankie I/8: 21:00). Auch versucht sie eine Beziehung zu einem Mann aufzubauen, der darin nur einen One-Night-Stand sah. Ihre Enttäuschung verdeutlicht, dass sie sich eine emotionale Bindung wünscht (vgl. Grace and Frankie I/7: 28:00). Letztlich geht sie eine Beziehung zu einem Kollegen ein (vgl. Grace and Frankie I/11: 19:00).

${ }^{8}$ Die Vernachlässigung der Familie über Beruf und Karriere und deren Sanktionierung ist ein in Familienserien häufig wiederkehrender Topos (vgl. Decker et al. 1996: 28).
} 
Die Verfolgung dieses Konsistenzprinzip ist integraler Bestandteil der Familienserien. Decker et al. zufolge liegt diesen Formaten stets „eine Art der Teleologisierung“ zugrunde, gemeint ist eine „zielhafte Ausrichtung des Lebens auf Erreichen bestimmter Zustände" (vgl. Decker et al. 1996: 81). Dieses Ziel ist - wenig verwunderlich, wenn man eine Serie als Familienserie versteht - die Gründung einer eigenen Familie oder die Harmonisierung der familiären Zustände (vgl. Decker et al. 1996: 74, 82). Das Leben von Charakteren, die dieses Ziel (noch) nicht erreicht haben, ist defizient. Streben sie nicht nach dem Erreichen dieses Ziels, handelt es sich meist um Negativcharaktere (vgl. Decker et al. 1996: 74).

Dieses familiäre Leben wird dabei scharf vom Außenraum abgegrenzt, d. h. von der umgebenden Gesellschaft, aus der Gefahr droht (vgl. Decker et al. 1996: 35). Dementsprechend stehen der Staat und sozialstaatliche Eingriffe der Familie gegenüber (vgl. Decker et al. 1996: 118). In Ozark ist der Staat gar Antagonist der Familie, wenn FBI-Ermittler die Geldwäschegeschäfte des Familienvaters Marty Byrde verfolgen und der Vater einer anderen handlungsrelevanten Familie im Gefängnis sitzt. Selbst in US-Serien der 1950er und 1960er Jahre - einer Zeit, die per se von relativ rigiden staatlichen und gesellschaftlichen Strukturen gekennzeichnet war - wurde ,Einmischung' von außen als unnötig inszeniert: "The family is a self-contained entity that can solve all crises on its own" (Leibman 1995: 153). Die Familie ist in den entsprechenden Formaten der dominante Raum, der alle anderen Räume weitgehend als irrelevant setzt oder von sich abhängig macht. Hier können Probleme gelöst und Konflikte geschlichtet werden.

Bei genauerer Untersuchung familiärer Systeme in Serien fällt auf, dass es sich bei dem, was als Alltag, als Normalität und Idealzustand gilt, dem Zustand also, dem die Charaktere durch Sanktionen zugeführt werden, keinesfalls um etwas handelt, das serienintern begründet wird. Vielmehr lässt sich „das Wertesystem der Familienserie als Setzung entlarven“" (vgl. Decker et al. 1996: 48). Was als Idealzustand gilt, beispielsweise die ,traditionelle', patriarchal strukturierte Familie der Serien der 1950er und 1960er Jahre, welche als Referenzpunkt, als Mythos der Perfektion für die folgenden Jahrzehnte diente, ist ein Postulat. Wie sich im weiteren Verlauf der Untersuchung und im folgenden historischen Überblick zeigen wird, ist dies insofern problematisch, da es sich bei diesen Postulaten um Ideale handelt, welche nicht mit der serienexternen Realität und ihren Gegebenheiten übereinstimmen - und in dieser Form nicht oder selten erreichbar sind. Zudem bieten die postulierten, stark emotionalisierten Wertesysteme wenig Raum zur verstandesgemäßen und/oder individuellen Lösung von Problemen. Die Norm, beispielsweise die Paarbindung, gilt im Weltmodell der Serien als unabdingbar und lässt keine Abweichung zu (vgl. Decker et al. 1996: 118). Darüber hinaus 
werden schwerwiegende gesellschaftliche Probleme nicht tatsächlich verhandelt oder gelöst, sondern in den emotionalisierten und geschlossenen, d. h. privaten Raum der Familie verlagert und hier einer Lösung zugeführt, die de facto keine ist (vgl. Decker et al. 1996: 119). ${ }^{9}$

Hier bestätigt sich die obige These: Familienserien errichten weniger selbst Weltmodell, sondern verarbeiten bereits bestehende Sichtweisen auf Familie. Dementsprechend erweisen sie sich als genuin konservativ, verweisen eher auf das Bestehende oder Bestandene als auf die Zukunft. Gerade in Serien und bestimmten Genres ,verfestigen sich mythische Strukturen [wie zum Beispiel das Ideal der Familie, Anm. des Verfassers], gerinnen zu immer wieder reproduzierbaren Formbestandteilen, wobei die Anschauungen von der Welt gerade nicht als Ideologie erscheinen, sondern als Natur" (Hickethier 1994: 61). Bestimmte Vorstellungen von Familie verhärten sich also auf eine Art, die einen Wandel und das Eindringen neuer Modelle erschwert. Durch das starre Wertemodell, einen Mangel an individuellen oder flexiblen Lösungen oder einen vorwärts gerichteten Blick fördern Familienserien - so Decker, Krah und Wünsch - „Ignoranz und Intoleranz“ (vgl. Decker et al. 1996: 119). Die Suche nach einer Idealfamilie und die damit einhergehende Verklärung einer, guten alten Zeit" lenken einerseits davon ab, dass es niemals ein ,goldenes Zeitalter' der Familie gab, und versperren andererseits den Blick auf die reale Diversität des familiären Lebens, für die generalisierende Lösungsansätze wenig sinnvoll erscheinen (vgl. Coontz 1992: 9). Zwar sind die Ergebnisse von Decker et al., welche hier meinen zentralen Referenzpunkt bilden, mittlerweile über 20 Jahre alt, sind aber insofern nach wie vor plausibel, da sie sich - bereits vor eingehender Analyse - mit den Inhalten der von mir untersuchten Serien decken. In Verbindung mit den oben vorgestellten Ergebnissen Robinsons, Skills, Jennings, Bryants et al. bestätigen sie den konservativen und gleichzeitig reduzierten Blickwinkel von Familienserien.

Es gilt, diese Thesen im weiteren Verlauf der Untersuchung zu bestätigen oder zu widerlegen. Unzweifelhaft ist, dass Familie nach wie vor eine zentrale Thematik in Serien darstellt und als Spiegel der Realität betrachtet wird, ohne zu berücksichtigen, dass fiktionale Weltmodelle zwar das Denken einer Gesellschaft abbilden, keinesfalls aber die Realität selbst. Es handelt sich um aus Texten

\footnotetext{
${ }^{9}$ So wird in der Serie Transparent die Transsexualität der Protagonistin Maura (zuerst Mort) zwar durchaus in einen gesellschaftlichen Rahmen eingebettet, der eigentliche Raum einer Lösungsfindung, in dem die dominante Verhandlung stattfindet, ist aber die Familie. Kinder und Verwandte müssen lernen mit der Transsexualität Mauras umzugehen, so wie Maura sich in dieser Rolle zurechtfinden muss. Alles andere ist sekundär und die gesamtgesellschaftliche Rolle transsexueller Menschen wird kaum thematisiert.
} 
erschließbares kulturelles Wissen. Fernsehfamilien und ihre allgemeine Modellierung bzw. Zusammensetzung sind daher nicht als Abbilder realer Familien zu betrachten - ebenso wenig, wie fiktionale Abbilder von Gesellschaft tatsächlich Gesellschaft wiedergeben. Vielmehr handelt es sich um die Darstellung von als wünschenswert oder nicht wünschenswert betrachteten Verhaltensweisen und Zuständen bzw. von als realitätsnah gedachten Modellen von Wirklichkeit. Was von Seite der Medienschaffenden als wünschenswert, realitätsnah oder - wichtiger noch - mit einem dominanten gesellschaftlichen Konsens vereinbar und insofern gut vermarktbar betrachtet wird, ist ebenso aufschlussreich über die Verhältnisse in einer Gesellschaft wie die - anhand von Zahlen und ,Fakten “ - abstrahierbaren Wissensmengen, die diesen Wünschen möglicherweise sogar entgegenlaufen.

\subsection{Die 1950er und 1960er Jahre: Ursprünge und Mythisierung der Idealfamilie}

Die Vorläufer von US-TV-Serien bildeten Radioprogramme der 1920er Jahre in Form von Episodenerzählungen (vgl. Hickethier 2003: 399) und sketchartigen Unterhaltungsformaten, beispielsweise Amos 'n' Andy-Show (1928-1960) ${ }^{10}$, in Radio und Fernsehen; vgl. Baker 2003: 17 f.). ${ }^{11}$ Mehr noch als die Fernsehserie per se wurde zunächst die Sitcom prototypisiert, welche gewissermaßen als Basis für spätere Entwicklungen diente. Neben diesen Vorläufern der Sitcom gewannen rasch von Unternehmen zu Werbezwecken finanzierte Formate, die Vorläufer der späteren Soap-Operas, an Popularität (vgl. Fröhlich 2015: 382 f.). ${ }^{12}$ Mit dem Ausbau des Fernsehnetzes in den USA Anfang der 1950er Jahre (vgl. Hickethier

${ }^{10}$ Die Amos 'n' Andy-Show, in der die weißen Komiker Freeman Gosden and Charles Correll zwei afroamerikanische Charaktere verkörperten, bis sie im Fernsehen durch afroamerikanische Schauspieler ersetzt wurden, ist aus heutiger Sicht als hochproblematisch zu beurteilen: Das Leben und die Kultur von Personen afroamerikanischer Abstammung wurde weniger repräsentiert als vielmehr zur Basis rassistischer Karikaturen von schwarzen Stereotypen (vgl. Leonard/Guerrero 2013: 3). Diese Art der Darstellung, die an negative Abziehbilder der vergangenen Jahrzehnte gemahnte, rief Empörung in Teilen der afroamerikanischen Bevölkerung hervor (vgl. Douglas 2003: 140).

${ }^{11}$ Zur frühen Entwicklung der Radiounterhaltung in den USA vgl. Fröhlich 2015: 378 ff. Das serielle Erzählen per se ist selbstverständlich wesentlich älter und seit Jahrtausenden Teil der menschlichen Erzähltradition. Scheinbar kommt das „Erzählen in Fortsetzungen oder auch in wiederkehrenden Episoden“ - so Hickethier - ,einem Grundbedürfnis menschlicher Unterhaltung nach und hat in der Fernsehserie nur ihre [sic] TV-bezogene massenmediale Form gefunden" (Hickethier 1991: 17 f.).

${ }^{12} \mathrm{Zu}$ Merkmalen der Seifenoper vgl. Fröhlich 2015: 385 ff. 
2003: 399) und dem massiven Anstieg der Popularität des Mediums - zwischen 1948 und 1960 stieg die Anzahl von Haushalten in den USA mit zumindest einem Fernsehen von $1 \%$ auf knapp $90 \%$ (vgl. La Rossa 2004: 57) - fanden ehemalige Radioprogramme wie Amos ' $n$ ' Andy oder I love Lucy (1951-1957, zuvor im Radio als My Favorite Husband) ihren Weg auf den Bildschirm. ${ }^{13}$ Insbesondere für das Familienbild der folgenden Jahrzehnte, aber auch allgemein für die populäre Fernsehunterhaltung waren die 1950er Jahre prägend.

Große Auswirkungen auf die Darstellungsweisen der 1950er und der 1960er Jahre hatte die strenge Kopplung an den „Motion Picture Production Code“ bzw. „Hays Code“, der 1929 entstanden war und sich sukzessive über die Jahrzehnte lockerte. Dieser regelte die Darstellung zahlreicher, sensibler' Themen wie Religion, Verbrechen und Gewalt, Sexualität oder Nationalgefühl. Auch die „,,sanctity of the institution of marriage" musste unangetastet bleiben" (Schleich/Nesselhauf 2016: 58, vgl. auch Leibman 1995: 95). Der „Televison Code of Good Practices", den die TV-Industrie 1951 erstellte, war weit umfassender und legte zudem diverse Pflichten Medienschaffender bezüglich der Verbesserung von Erziehung und Kultur (,advancement of education and culture“) fest (vgl. Leibman 1995: 105). Formate dieser Zeit waren bereits aufgrund der Zensur zu einer unkritischen und idealisierten Darstellung verpflichtet - auch wenn es sich nicht selten um eine durch Vorsicht bedingte Selbstzensur der Autoren handelte (vgl. Leibman 1995: 105). ${ }^{14}$ Zudem hatten der Zweite Weltkrieg ebenso wie die Große Depression der 1930er Jahre die Erinnerungen der US-Amerikaner an ein ,normales' Familienleben getrübt und ein besonderes Bedürfnis nach Stabilität geschaffen. Der Kalte Krieg stärkte die Bedeutung der konformistischen und konsumierenden Familie weiter. Darstellungen von Familien, die im Kapitalismus aufgingen, dienten als Bollwerk gegen den Kommunismus (vgl. Kutulas 2016: 17 f.). ${ }^{15}$

\footnotetext{
${ }^{13}$ Mit Beginn der 1960er Jahre wurden auch in der Bundesrepublik US-Serien, ,gezielt eingekauft und entwickelten sich zu wesentlichen Bestandteilen der populären Fernsehkultur“ (Hickethier 2003: 399). Zu einem Überblick über die Entwicklung der Serie in der BRD verweise ich auf Hickethier 2003: $399 \mathrm{f}$.

${ }^{14}$ Um den Sponsoren ebenso wie den moralischen Ansprüchen der Zuschauenden gerecht zu werden, fand zusätzlich eine senderinterne Regulierung statt und die Sponsoren der Formate nahmen direkten Einfluss auf deren Gestaltung (vgl. Leibman 1995: 107). Zudem - dies ist nicht im eigentlichen Sinne als Zensur zu verstehen - wurden Serienschaffende dazu angehalten, beworbene Produkte offensiv in den Serien zu platzieren (vgl. Leibman 1995: 110 f.). Zur Entwicklung und sukzessiven Lockerung der Zensurbestimmungen in den USA möchte ich verweisen auf Leibman 1995: $94 \mathrm{ff}$.

${ }^{15}$ Auch für die deutsche Serie der 1950er und 1960er Jahre konstatiert Hickethier eine „Versöhnungssehnsucht“ in Opposition zum Zweiten Weltkrieg und zum Kalten Krieg (vgl. Hickethier 1994: 60).
} 
In the 1950's the networks were determined to reach as many consumers as possible - large family groups who would be interested in furnishing and feeding a household. One of the best ways to encourage consumer families to watch a program and buy the product was by example, presenting television consumer families as "typical" visions of American family life that the viewer would want to emulate. (Leibman 1995: 252)

Im Interesse der Medienschaffenden lag es demzufolge eben nicht, das realistische Bild einer von den Nachwehen des Krieges und der Depression gebeutelten Gesellschaft zu zeigen, sondern ein Idealbild zu konstruieren, an dem sich die US-amerikanischen Familien orientieren, dem sie nacheifern konnten.

Aus diesen Faktoren ergab sich eine klar hierarchisierte und geordnete Familiendarstellung mit deutlich patriarchaler Ausrichtung. Interessanterweise waren den Serien, welche genau diese Struktur festigten und auch bis heute im Gedächtnis blieben, wenig referenzierte Formate wie Mama (1949-1957) oder The Goldbergs (1949-1956, die erste TV-Family-Sitcom, vgl. Neuwirth 2006: 2) vorausgegangen. Beide Serien zeigten das Leben von Einwanderer- und Arbeiterklassefamilien, im Falle von Mama norwegische Einwanderer im San Francisco der Jahrhundertwende und in The Goldbergs eine jüdische Familie in der Bronx. ${ }^{16}$ In beiden Serien war die Mutterrolle deutlich prominenter und mit größerer Autorität ausgestattet als die Vaterrolle (vgl. Brooks 2005: 13, 19). Im Gegensatz zu den späteren Patriarchen wurden diese Väter der Arbeiterklasse als ungeschickt und unbeholfen dargestellt, während die Mutter Probleme löste (vgl. Brooks 2005: 2) ${ }^{17}$ Auch die populäre Sitcom I love Lucy (1951-1957) zeigte eine eher subversive Protagonistin, die immer wieder versuchte, aus ihrer Rolle als Hausfrau auszubrechen, diese Ambitionen aber dann aufgrund ihrer Schwangerschaft

\footnotetext{
${ }^{16}$ Schwerwiegendere gesellschaftliche Probleme sparten diese Serien, wie auch die späteren Formate, weitgehend aus - so wurde z. B. in The Goldbergs nie der US-amerikanische Antisemitismus verhandelt (vgl. Brooks 2005: 20).

${ }^{17}$ In den 1950er Jahren lässt sich eine generelle Diskrepanz zwischen der Darstellung von Arbeiterklasse- und Mittelklasse-Vätern feststellen: Väter der Arbeiterklasse waren eher Ziel von Scherzen und wurden als unzulängliche und komische Figuren dargestellt (vgl. LaRossa 2004: 60, vgl. Butsch 2015: 115), wohingegen TV-Väter der Mittelklasse erfolgreicher als ihre weniger wohlhabenden Gegenstücke waren (vgl. Butsch 2005: 117). Dies lässt sich mit dem idealisierten Bild der Mittelklasse als gesellschaftlichem Leitstern in den Sitcoms der 1950er und 1960er Jahre in Einklang bringen.
} 
weitgehend aufgeben musste (vgl. Kutulas 1998: 15). ${ }^{18}$ Die Dominanz der Protagonistin ergab sich auch daraus, dass die Schauspielerin Lucille Ball - die namensgebende Lucy - der Star der Serie war.

Populäre Serien wie Leave It To Beaver (1957-1963), The Adventures of Ozzie and Harriet (1952-1966) oder - mit kennzeichnendem Namen - Father Knows Best (1954-1960) lösten sich vom Milieu der Arbeiterklasse und wandten sich der Mittelklasse zu, die eher dazu geeignet war, die gewünschte Idealstruktur zu präsentieren. Tendenzen weiblicher Dominanz wurden in eine Familienstruktur überführt, die Matthew Henry folgendermaßen charakterisiert:

Atop the nuclear family was posited a patriarchy in which the father was portrayed as knowing, correct, and superior to his wife and children, a structure that worked to prevalent sexual stereotypes. (Henry 2003: 265)

Der Ehemann fungierte demnach als alleiniger Brotverdiener und ,zentrale Autoritätsinstanz" (Dechert 2018: 30), der die Regeln der Familie vorgab und Konflikte schlichtete. Die Mutter war ,attractive, witty, sociable, and supportive of her husband's authority" - sie und die weitgehend braven Kinder erkannten die Autorität des Vaters stets an (vgl. Tueth 2003: 136 in Bezug auf Father Knows Best). Ozzie Nelson, der Familienvater in The Adventures of Ozzie and Harriet war ein typischer „alpha male“, dessen Wort respektiert wurde und der seinen drei jungen Söhnen den rechten Weg wies (vgl. Brooks 2005: 28). ${ }^{19}$ Seine Ehefrau Harriet war eine adrette Hausfrau und Mutter, die 1952 zur „Hollywood Mother of the Year“ gewählt wurde (vgl. Brooks 2005: 29). Damit ähnelte sie June Cleaver, Mutter in Leave It to Beaver, einer Serie, die ebenfalls eine hingebungsvolle Mutter und einen strengen, aber geduldigen Vater bei der Erziehung ihrer beiden Söhne zeigte, wobei der Vater immer das letzte Wort hatte. Die Söhne, insbesondere der jüngere Beaver, waren - wenngleich sie gelegentlich Fehler machten - wohlmeinend und gut erzogen (vgl. Brooks 2005: 37 f.). Die Andersons in Father Knows

\footnotetext{
${ }^{18}$ Die Serie The Honeymooners (1955-1956) zeigt ebenfalls eine schlagfertige Ehefrau, die sich gegen einen autoritären Ehemann behaupten konnte. Die konstanten Gewaltandrohungen des Ehemannes Ralph Kramden gegenüber seiner Ehefrau - „One of these days, Alice, one of these days - Pow! Right in the kisser!“ (vgl. Neuwirth 2006: 1) - können aus heutiger Sicht nur befremdlich erscheinen, auch wenn Kramden seine Drohungen nie umsetzte und abschließend stets die Liebe zu seiner Frau beteuerte (vgl. Brooks/Marsh 2007: 632).

${ }^{19}$ Die starke Einbeziehung des Vaters in die Erziehung der Söhne wurde auch außerhalb des TV allgemeingesellschaftlich gewünscht, da durch die „Abwesenheit männlicher Rollenmodelle eine Zunahme von Homosexualität unter männlichen Jugendlichen sowie ein Anstieg jugendlicher Straftaten“ befürchtet wurde (Dechert 2018: 31). Ein zu großer Einfluss der Mutter galt als Grund für eine eventuelle Verweichlichung der Söhne.
} 
Best waren das Musterbeispiel einer US-amerikanischen Familie, in der die strengen, traditionellen Eltern von ihren Kindern das Verhalten kleiner Erwachsener erwarteten und Spaß und Vergnügen weitgehend ausgespart wurde (vgl. Leibman 1995: 124 f.). Jedwede Grenzüberschreitung, etwa die Berufsambitionen der Tochter (vgl. Leibman 1995: 180) oder die Vernachlässigung der häuslichen Pflichten durch Mutter Margaret (vgl. Leibman 1995: 194), wurden immerzu sanktioniert und in gewohnte Wege zurückgeführt. Die Väter dieser Familien waren deren moralisches Zentrum und die Mütter gaben ihre Identität selbstlos für die Familie hin (vgl. Kutulas 1998: 16). Die familiäre Machtstruktur, zu der auch die Autorität von männlichen gegenüber weiblichen Kindern zählte schließlich handelte es sich hierbei um die zukünftigen Väter -, wurde durch narrative Strategien gefestigt. Dazu zählten beispielsweise die Zentrierung des Vaters in familiären Konversationen und seine visuelle wie narrative Omnipräsenz (vgl. Leibman 1995: 118).

Es ist an dieser Stelle beinahe redundant zu erwähnen, dass nicht weiße Familien kaum dargestellt wurden. Selbst einzelne nicht US-amerikanische Figuren traten selten auf oder wurden - wie Frank Smith, der mexikanische Gärtner der Familie Anderson in Father Knows Best - als den weißen Protagonist/inn/en allgemein unterlegen dargestellt (vgl. Leibman 1995: 166). Allgemein herrschten im TV der 1950er und 1960er Jahre negative Stereotypen von nicht weißen USAmerikanern, insbesondere von Personen afroamerikanischer Abstammung, vor (vgl. Leonard/Guerrero 2013: 10). Afroamerikanische Familien wurden gesellschaftlich „stigmatisiert und pathologisiert“ und als das „Gegenstück“ zur idealen weißen Kernfamilie betrachtet (vgl. Dechert 2018: 35). Im Zuge der Bürgerrechtsbewegung lehnten afroamerikanische Darstellende diese Rollen zunehmend ab und schufen somit ein Vakuum an entsprechenden Charakteren (vgl. Cutts 2013: 191).

Ebenso wenig fanden gesellschaftliche Probleme wie der extreme Rassismus, der Vietnamkrieg oder die aufkeimende Bürgerrechtsbewegung Erwähnung (vgl. Oswald 2003: 316, vgl. Butsch 2005: 115). Vielmehr handelte es sich bei den dargestellten Familien fast ausschließlich um Angehörige der weißen Mittelschicht, die in „Suburbs“, Vororten außerhalb der Stadt, wohnten und somit scheinbar fern von allen gesellschaftlichen Problemen lebten (vgl. Morreale 2003: 4). Familien waren quasi autarke Systeme, die ihre wenig schwerwiegenden Probleme intern lösen konnten und in denen die weitgehend stereotypen und konsistenten Charaktere zufrieden mit ihrem Platz in Familie und Gesellschaft waren (vgl. Butsch 2005: 115).

Die Aussparung der sozialen Realität - damit einhergehend die Diskriminierung der nicht weißen Bevölkerung - sowie die bewusste Trennung der 
Schauplätze von Orten des öffentlichen oder beruflichen Lebens verdeutlichen die bereits erwähnte Intention der Formate, Stabilität und Ordnung zu repräsentieren. Die Diskrepanz zur tatsächlichen Familienrealität war enorm. Die auf die Vormachtstellung des Patriarchats ausgerichteten Bestrebungen, die auch in der Gesellschaft stattfanden, stellten ,zum damaligen Zeitpunkt einen Rückschritt im Vergleich zur bisherigen Liberalisierungs- und Gleichstellungstendenz der Familienstrukturen und der Geschlechterrollen dar“ (vgl. Kelsch 2019: 28). Die alternativlose Bindung an Heim und Herd war nicht die freie Entscheidung der Frauen, welche sich während des Zweiten Weltkrieges eine gewisse berufliche Unabhängigkeit erworben hatten. Nach Ende des Krieges wurden zahlreiche Versuche unternommen, diese Entwicklung zu revidieren und Frauen aus der Arbeitswelt oder in schlechter bezahlte Jobs zu drängen (vgl. Coontz 1991: 33 f.). Die (sexuelle) Misshandlung von Kindern und Ehefrauen wurde entproblematisiert bzw. ignoriert (vgl. Coontz 1991: $31 \mathrm{f}$.). Alkohol und Beruhigungsmittel boten einen Ausweg aus den gefängnisartigen Zwangsstrukturen der Familie und dem gesellschaftlichen Erwartungsdruck (vgl. Coontz 1992: 40, vgl. Dechert 2018: 32 f.). ${ }^{20}$ Diese Problematiken wurden indes in den medialen Idealfamilien vollkommen ausgeklammert. Das Resultat war ein übersteigertes Ideal der Hausfrau und der Mutterschaft, das zu einer Stigmatisierung jeder Abweichung bzw. jeden Mangels an Erfüllung in dieser Rolle als unnatürlich und anormal führte.

Aufgrund der Makellosigkeit und der Abwesenheit jeglicher Dysfunktionalität in der Sitcom der 1950er Jahre sind es gerade die Family-Sitcoms der 1950er Jahre, die bis heute das Verständnis von traditioneller Familie bzw. Idealfamilie prägen (vgl. Coontz 1992: 21 f.). Aus dieser Art der Darstellung, die sich in den 1960er Jahren weitgehend fortsetzte, entwickelte sich ein Modell der FernsehFamilie, das nach wie vor normativ ist. Es sind die in dieser Zeit aufgestellten Modelle, welche - zumindest in der US-amerikanischen Medienlandschaft - den Prototyp dessen darstellen, wie die ideale Familie zu sein habe, obgleich es sich um eine Mischung von Strukturen, Werten und Verhaltensweisen handelt, die so nie gemeinsam existierten (vgl. Coontz 1992: 2). ${ }^{21}$

${ }^{20}$ Andre Dechert weist zudem darauf hin, dass der ,ökonomische Wohlstand, wie ihn die Andersons, Cleavers und Nelsons lebten “ für viele Familien der US-amerikanischen Mittelschicht ,in weiter Ferne“ lag (Dechert 2018: 34). Zahlreiche Frauen mussten einen Beruf ergreifen, ,um das finanzielle Überleben ihrer Familien sicherzustellen“ (Dechert 2018: 34). Dieser Widerspruch von medialer Idealdarstellung und Realität zeigt den eskapistischen Charakter der Serienfamilien und der inszenierten Geschlechterrollen deutlich auf.

${ }^{21}$ Stephanie Coontz beschreibt die traditionelle Familie als Mischprodukt von Vorstellungen und Charakteristika des mittleren 19. Jahrhunderts sowie der 1920er Jahre, zu dem gewisse Ideen der 1950er Jahre addiert wurden (vgl. Coontz 1992: 2 f.). Gerade als Basis eines 
Betrachtet man Robinsons und Skills Ergebnisse zur Familienzusammensetzung in Serien, so fällt auf, dass sich selbst in den 1950er Jahren lediglich etwa $38 \%$ der TV-Familien aus Eltern und Kindern zusammensetzten, die gemeinsam als Kernfamilie unter einem Dach wohnten, in den 1960ern 24,5\% - ein Wert, der sich bis 1995 (Endpunkt der Untersuchung von Robinson und Skill) nicht bedeutend verändert hat. Addiert man die ca. $18 \%$ Darstellungen einer erweiterten Familie in den 1950ern und die knapp $30 \%$ in den 1960ern zu obigen Zahlen hinzu, übersteigt das Ergebnis jeweils deutlich die $50 \%$ und lässt durchaus auf eine Dominanz geschlossener familiärer Verbände im TV schließen. Dieser Wert unterliegt bis 1995 nur geringen Schwankungen (zu allen Angaben vgl. Robinson/Skill 2001: 151). Ebenso relevant wie die ,realen' Zahlen ist aber, dass vor allem die TV-Familien der 1950er Jahre im Gedächtnis blieben, die dem geschilderten Ideal entsprachen und abweichende Familien, z. B. alleinerziehende Elternteile oder Großfamilien, in den Hintergrund traten. Dies zeigt den normativen Einfluss des Familienmodells der 1950er Jahre.

Die in den 1950er Jahren gelegten Strukturen wurden zunächst fortgeführt, wenn auch - einhergehend mit der Zunahme der Scheidungsraten - die Anzahl alleinerziehender Eltern in Serien zunahm (vgl. Brooks 2005: 52, vgl. Dechert 2018: 2). Weiterhin dominierte das ,white, suburban, married, two-parent couple with children" die Fernsehbildschirme. Es wurden keine abweichenden Modelle präsentiert: „Families that were different because of race, sexual preference, divorce, or some other factor were simply not represented; they were outside the dominant ideal of family" (Oswald 2003: 312). Aniko Bodroghkozy charakterisiert das Fernsehen der 1960er Jahre als „,vast wasteland“ in Anlehnung an eine Aussage von Newton Minow, einem ehemaligen Vorsitzenden der US-Kommunikations-Behörde FCC. Das Programm dieser Jahre sei auf die Vermeidung jeglicher Kontroversen und Konflikte ausgerichtet gewesen, die in direktem Gegensatz zu den massiven gesellschaftlichen Umbrüchen wie dem Kennedy-Attentat, dem Vietnamkrieg und der Bürgerrechtsbewegung stand (vgl. Bodroghkozy 2003: 81). Dies spiegelte sich in Serien wie The Andy Griffith Show (1960-1968) wider. Hier erzog ein verwitweter Kleinstadtsheriff seinen Sohn mit altmodischer Weisheit, während beide von einer älteren Haushälterin aufopferungsvoll und liebevoll versorgt wurden (vgl. Brooks 2005: 56 f.). Ebenso wie in der Western-Serie Bonanza (1959-1973), in der ein verwitweter Rancher als Vorbild für seine drei - bereits erwachsenen - Söhne fungierte (vgl. Brooks

\footnotetext{
Vergleichs idealisierter Wunschvorstellungen von Familie mit der Realität ist Coontz 'The way we never were. American families in the nostalgia trap (Coontz 1992) zur weiterführenden Lektüre zu empfehlen.
} 
2005: 48), wichen hier die ,realitätsfernen' Suburbs ländlichen Gegenden und wurden - im Falle von Bonanza oder The Flintstones (1960-1966) - sogar zeitlich in die Vergangenheit verlagert. Ähnlich eskapistische Tendenzen, die der angespannten politischen Lage zuwiderliefen oder wohl eher aus dieser geboren wurden, zeigten die Serien My favorite Martian (1963-1966), Bewitched (1964-1972), The Addams Family (1964-1966) oder The Munsters (1964-1966), welche fantastische Elemente wie Außerirdische, Monster und Hexerei enthielten (vgl. Morreale 2003: 88 f.). ${ }^{22}$ Obwohl sich die Charaktere der letzteren beiden Beispiele aus einer Mischung aus Monstern, Werwölfen, Vampiren und ähnlichen Kreaturen zusammensetzten, die an morbiden Orten lebten und exzentrische Sitten pflegten, galt familiärer Zusammenhalt und elterliche Fürsorge weiterhin sehr viel, traditionelle Familienwerte wurden nicht in Frage gestellt (vgl. Brooks 2005: 71, 72). Unter der Oberfläche von Bewitched, einer Serie, in der eine Hexe versuchte, ihre Zauberkräfte zum Wohle ihres Ehemannes aufzugeben, war nach Judy Kutulas bereits die Furcht vor einer ,Entmännlichung' des Mannes durch moderne Frauen deutlich angelegt - eine Thematik, die mit den fortschreitenden 1960er Jahren bedeutsamer werden sollte (vgl. Kutuals 1998: 16). Laut Dechert stellten die zahlreichen übernatürlichen Sitcoms der 1960er Jahre die Frage: Was ist Normalität? (vgl. Dechert 2018: 40). Griffen sie zwar nicht direkt die konservativen familiären Normen an, so trafen sie doch in gewissem Sinne den Zeitgeist. Der Befürchtung jugendliches Publikum zu verlieren begegneten die Sender in den 1960er Jahren mit zahmen und auf Konformität bedachten Shows, die vor allem Musik und Musik-Stars in den Mittelpunkt stellten (vgl. Bodroghkozy 2003: 81 f.).

Mit dem Ende der 1960er Jahre geriet das Dogma der absoluten Stabilität ins Wanken:

By the late 1960s and the Johnson era, an emerging critique of the status quo is observable in popular satires such as How to Succeed in Business Without Really Trying (1967). In that Broadway hit, songs such as "A Secretary is not a Toy" and "Happy to Keep His Dinner Warm" suggest an emerging unrest in suburbia. Unrest turned into rebellion when the civil rights movement and the Vietnam War raised the consciousness of a booming generation of young people who had both the voice and the buying power to be heard. (Oswald 2003: 317)

\footnotetext{
${ }^{22}$ Eine weitere signifikante Entwicklung jenseits der Inhalte war, dass seit Mitte der 1960er zunehmend Programme in Farbe ausgestrahlt wurden (vgl. Morreale 2003: 89).
} 
Zunehmend schwand die Autorität der Fernseh-Eltern und den älteren Kindern wurde mehr Unabhängigkeit zugestanden (vgl. Kutulas 2016: 20). Das Interesse des jungen Publikums, der Baby-Boomer-Generation für die eskapistischen Serien des vorangegangenen Jahrzehnts, war gering. Krieg und sozialer Wandel traten in den Mittelpunkt des Interesses (vgl. Kutulas 1998: 18). Zu den ersten Formaten, die versuchten, dem Mentalitätswandel gerecht zu werden und die US-amerikanische Gegenkultur abzubilden, gehörten Shows und Serien wie The Smothers Brothers Comedy Hour (1967-1969), The Mod Squad (1968-1973) und Rowan and Martin's Laugh-in (1968-1973). In Teilen hatten diese Formate, beispielsweise The Smothers Brothers, ein Comedy-Duo, das tendenziell gegen Krieg und für eine Gegenkultur einstand, mit den rigiden Zensurbestimmungen und dem allgemeinen Druck von Seiten der Sendeanstalten und der politischen Netzwerke zu kämpfen (vgl. Bodroghkozy 2003: 83, vgl. Neuwirth 2006: ix).

Auch in Bezug auf die Familienserie fanden Veränderungen statt: Hatte ethnische Diversität bis zu diesem Zeitpunkt keinerlei Rolle gespielt - $97 \%$ der TV-Familien waren weiß -, stand 1968 in Julia (1968-1971) die erste afroamerikanische Familie im Zentrum der Handlung. Schauspielerin Diahann Carroll verkörperte hier Julia Baker, eine verwitwete, alleinerziehende Krankenpflegerin (vgl. Robinson/Skill 2001: 147). Julia wurde aufgrund diverser Faktoren kritisiert. Die afroamerikanische Zuschauerschaft bemängelte vor allem die Abwesenheit einer Vaterfigur - Julias Ehemann war vor Beginn der Handlung im Vietnamkrieg gefallen (vgl. Dechert 2018: 55, vgl. Bodroghkozy 2012: 181). Die erste afroamerikanische TV-Familie, seit den offen rassistischen Serien der frühen 1950er Jahre, war somit eine - im Vergleich zu den weißen Familien - defiziente Familie. Die Darstellung der kritischen Rolle des männlichen Afroamerikaners und seiner gesellschaftlichen Position wurde somit ausgespart (vgl. Bodroghkozy 2012: 200). Zwar wurde diese Serie oft kritisiert, da sich die Protagonistin in einer Zeit voller Unruhen in der afroamerikanischen Bevölkerung wegen des präsenten Rassismus scheinbar mühelos in die überwiegend weiße Mittelklasse-Welt einfügte, dennoch stellt sie durch die zentrale Repräsentation eines afroamerikanischen Charakters eine wichtige Verbindung zwischen den trivialen Sitcoms der 1960er und den folgenden sozialrelevanten Formaten der 1970er Jahre dar (vgl. Morreale 2003: 89). 


\subsection{Die 1970er Jahre: Experiment, Abweichung und soziale Problematiken}

In den 1970er Jahren wuchs die journalistische Kritik an den verklärten Idealfamilien des Fernsehens der vorangegangenen zwei Jahrzehnte, die als Widerspruch zur tatsächlichen Lebensrealität dieser Zeit wahrgenommen wurden. Bürgerrechtsbewegung und erstarkender Feminismus trugen zu einem Umdenken hinsichtlich gesellschaftlicher und politischer Faktoren, u. a. der Familie, bei (vgl. Dechert 2018: 43 f.). Eine Abweichung von der bisher medial präferierten Familienstruktur, die den Vater als alleinigen Brotverdiener und die Mutter als Hausfrau zeigte, war auch deswegen notwendig, da diese aufgrund gestiegener Lebenshaltungskosten und einer problematischen Lohnentwicklung nicht mehr der Realität entsprach - oft mussten beide Eltern arbeiten gehen (vgl. Dechert 2018: 46).

,Sozialrelevante' Serien, die sich mit zeitgenössischen Problemen auseinandersetzten, traten an die Stelle der ruralen TV-Ideale und Fantasiewelten des vorherigen Jahrzehnts. In den Serien der 1970er Jahre wurden Themen aufgebracht, welche zuvor nicht verhandelt worden waren: Abtreibung, Vergewaltigung, interreligiöse Heiraten, Armut und Antikriegsstimmung (vgl. Brooks 2005: 87). Zudem wurden offen Problematiken wie Tod, Alkoholismus, Scheidung, Geschlechterrollen und die Konflikte zwischen den Ethnien angesprochen (vgl. Morreale 2003: 151 f., vgl. Levine 2003: 90). ${ }^{23}$ Charaktere und Charakterbeziehungen gewannen an Komplexität und Tiefe. ${ }^{24}$

\footnotetext{
${ }^{23}$ Serien wie Charlie's Angels (1976 bis 1981) hatten einen deutlich sexuellen Unterton, was zuvor nicht möglich gewesen wäre, auch wenn dieser - im Vergleich zu späteren Formaten und aus heutiger Perspektive - eher harmlos ausfiel. Ebenso nahmen Gewaltdarstellungen zu, etwa in Actionserien (vgl. Levine 2003: 93).

${ }^{24}$ Da der Begriff ,,komplex“ an sich unpräzise ist, möchte ich ihn für einen bestimmten Verwendungskontext im Rahmen dieser Untersuchung definieren: Spreche ich von ,komplexen Charakteren", so meine ich nicht stereotype Charaktere mit ambivalenten Charaktereigenschaften und einer Motivation, die im Weltmodell weder eindeutig positiv noch negativ konnotiert ist. Komplexe Charakterbeziehungen zeichnen sich durch ambivalente Verhältnisse der Figuren zueinander und einem daraus resultierenden Konfliktpotenzial aus. Ein komplexes Weltmodell nimmt keine klar ersichtliche Trennung in ,gut“ und „,böse“, ,,richtig“ oder ,falsch“ vor, sondern umfasst einen Graubereich und macht eine genaue Abstraktion notwendig - dies heißt indes nicht, dass im Kern kein klares Normgerüst besteht. Eine komplexe Erzählstruktur muss, z. B. aufgrund achronologischen Erzählens, erst entschlüsselt werden etc. Als „komplex“ sollen hier also uneindeutige und mehrdimensionale Darstellungsformen verstanden werden, die sich einer einfachen Beschreibung entziehen und zum vollständigen Verständnis eine genaue Untersuchung voraussetzen. Damit möchte ich mich von einer wertenden Komplexitätsbezeichnung abgrenzen, die „komplex“ mit ,von höherer textueller Qualität" gleichsetzt.
} 
The Mary Tyler Moore Show (1970-1977), deren Protagonistin eine werktätige, alleinstehende Frau war, die nicht heiratete und keine Kinder bekam, war eine der ersten Sitcoms, die ein veränderte Perspektive auf gesellschaftliche Möglichkeiten abbildete (vgl. Morreale 2003: 151, vgl. Brooks 2005: 2). Durch eine drastische Abweichung vom bisherigen Familienideal erregte vor allem die Sitcom All in the Family (1971-1979) großes Aufsehen:

In January 1971, All in the Family premiered, sending shock waves through the culture because of its rendering of a family decidedly unlike the Cleavers [die Familie aus Leave it to Beaver, Anm. des Verfassers]. Its main characters are Archie and Edith Bunker, their daughter Gloria, and Gloria's husband, Michael. Gloria and Michael are baby boomers, open to the new political, social, and cultural possibilities of the 1960s. Archie and Edith represent the older generation, raised on the deprivation and sacrifice of the Depression and the unabashed patriotism of World War II. These two generations fight all the time about the war in Vietnam, sexual attitudes, race, religion and women's roles, but the subtext is nearly always the same. Archie expects to be patriarch of his family with all the attendant status and power of this position. Gloria and Michael reject both his authority and his model of family, actions privileged by the show's presentation of Archie as ignorant and bigoted [...]. Even though his wife is subservient [...], Archie is not the lord and master of his castle. (Kutulas 2016: 21)

Der Erfolg der Serie, welche zwar zunächst schlechte Einschaltquoten verzeichnete, sich aber rasch ein großes Publikum aufbaute (vgl. Morreale 2003: 151), trug dem Zeitgeist Rechnung.

All in the Family, beispielhaft für die Kritik der jüngeren Generation an familiären Dynamiken der 1950er Jahre und den Konflikt zwischen den Generationen, zeigt ein Zerbrechen autoritärer Strukturen (vgl. Kutulas 2016: 21 f., vgl. Dechert 2018: 64). Elterliche Autorität wurde ebenso abgelehnt wie Materialismus (vgl. Kutulas 2016: 20). Um dem jüngeren Publikum zu entsprechen, wandelten nun auch Fernseh-Familien ihre Form. Die Autorität der Fernseh-Väter schwand ebenso wie ihre Stellung als zentrale Familienmitglieder (vgl. Kutulas 2016: 22 f.). TV-Mütter waren die eigentlichen Autoritätspersonen, wurden allerdings ebenso zur Angriffsfläche für Spott. Mit dem konservativen Modell der Mutterschaft aus den 1950er und 1960er Jahren standen sie in Opposition zu den von der Frauenbewegung beeinflussten Töchtern. Diese waren eher an ihrer Freiheit und ihrer Arbeit interessiert als an Heirat und einem Leben in der Vorstadt. Ein Leben als Hausfrau und Mutter verlor somit an Attraktivität (vgl. Kutulas 2016: 23). Dementsprechend traten vermehrt Frauen auf, die - wie etwa in den Serien Rhoda (1974-1984), Phyllis (1975-1977) oder One Day at a Time (19751984) - ihr Leben ohne die omnipotenten Väter der 1950er und 1960er bestritten (vgl. Levine 2003: 91). Maude, ein Charakter des gleichnamigen Sitcom-Ablegers 
von All in the Family (1972-1978), war nicht nur mehrfach geschieden, sondern sorgte mit ihrer Entscheidung für eine Abtreibung für eine mediale Kontroverse - mehrere Sender verweigerten eine Ausstrahlung der entsprechenden Episoden (vgl. Morreale 2003: 152, vgl. Dechert 2018: 65).

Eine zunehmende Auswahl an alternativen Modellen zur aus Notwendigkeit zusammengehaltenen Familie der vorangegangenen Jahrzehnte, z. B. das SingleLeben, führte zu einer weiteren Destabilisierung des Modells der Kernfamilie (vgl. Kutlas 2003: 23 f.). Wie sich an Formaten wie Three's Company (19771984), $M * A * S * H$ (1972-1983) oder WKRP in Cincinnati (1978-1982) zeigt, gewannen ,Wahlfamilien' aus Freundschaften, Mitarbeitenden etc. an Attraktivität gegenüber einer instabilen biologischen Familie (vgl. Kutlas 2003: 24). Diese Serien zeigten auch junge, berufstätige Frauen, die sich gegen männliche Avancen zur Wehr setzen konnten (vgl. Kutulas 1998: 19).

Familien wie in All in the Family hatten zudem die Vororte der Mittelklasse verlassen und zeigten das Leben von Arbeiterfamilien. Bezüglich ethnischer Diversität übertrafen die Serien der 1970er Jahre die vorherigen und auch die folgenden Jahrzehnte. $14 \%$ der dargestellten Familien waren afroamerikanisch, andere Ethnien waren weiterhin wenig vertreten (vgl. Robinson/Skill 2001: 148). Sogenannte „ethnic sitcoms“ wie Sanford and Son (1972-1977) und Diff'rent Strokes (1978-1986), die das Leben von afroamerikanischen Familien darstellten, konnten ihre Position behaupten. Zwar wurden hier weiterhin negative Stereotype, z. B. in Hinblick auf afroamerikanische Männer und Väter, gefestigt und die Familien oft als defizient oder dysfunktional dargestellt (vgl. Dechert 2018: $56 \mathrm{f}$.), doch konnten zugleich gesellschaftlich vielfältigere Formate ihren Weg ins Fernsehen finden (vgl. Morreale 2003: 153). The Jeffersons (1975-1985) - ebenfalls ein Spin-Off von All in the Family - war beispielsweise die erste Serie, die ein Ehepaar mit unterschiedlicher ethnischer Herkunft zeigte (vgl. Brooks 2005: 109). Homosexuelle Charaktere wurden ,nicht länger wie in den 1950er und 1960er Jahren ausgeblendet“, sondern ,angesichts der Bemühungen homosexueller Lobbygruppierungen zumindest in TV-Serien zunehmend ,positiver" dargestellt" (Dechert 2018: 48 f.).

Trotz des deutlichen Konfliktpotenzials der Serien muss zweierlei betont werden. Erstens wurde der Versuch unternommen, dem jüngeren Publikum zu entsprechen, wobei weiterhin darauf geachtet wurde, die älteren Zuschauenden nicht zu verärgern. Ein deutlich komischer Unterton entschärfte Konflikte und Extreme (vgl. Levine 2003: 91). Überdies existierten zwar TV-Frauen, die ein ,freies' Leben, fern von häuslichen Zwängen führten, offener Feminismus wurde jedoch nach wie vor negativ dargestellt. Ebenso wie die Lesben- und Schwulenrechtsbewegung, die als zu ,gefährlich` für die Primetime wahrgenommen 
wurde (vgl. Dalton/Linder 2016: 105). Als Reaktion auf Kritik wegen gewalttätiger und sexueller Inhalte begannen die Sendeanstalten Mitte der 1970er Jahre Serien auszustrahlen, die als ,Gegenbewegung ' zu den zuvor genannten Serien zu verstehen sind (vgl. Lichter et al. 1994: 154). Die Mittelklasse-Familie Cunningham aus Happy Days (1974-1984), einer Serie, die sogar von Mitte der 1950er bis Mitte der 1960er Jahre spielte, repräsentierte wieder die Familienwerte der 1950er Jahre. Familienvater Howard war ein Alleinverdiener, der nach der Arbeit zu seiner liebenden Familie heimkehren konnte. Mutter Marion war eine etwas zerstreute Hausfrau, die ausgesprochen fürsorglich gegenüber ihrer Familie auftrat (vgl. Brooks 2005: 100). Die Serie verfolgte den Lebensweg der Familienmitglieder über ein Jahrzehnt hinweg (vgl. Brooks 2005: 101). Besonders hervorzuheben sind ebenso The Waltons (1972-1981), eine Großfamilie in den 1930er Jahren, die in gewisser Hinsicht dem ruralen Eskapismus der 1960er Jahre entsprach. Die Familie Walton - Großeltern, deren Sohn, dessen Frau und deren sieben Kinder - lebten in engem Zusammenhalt im ländlichen Virginia. Was aufgrund der Nachwehen der großen Depression an Geld fehlte, wurde durch Liebe kompensiert (vgl. Brooks 2005: 94). Familienvater John war ein hartarbeitender Mann, seine Frau Olivia sehr religiös und alle Kinder schlossen im Verlauf der Serie die Schule ab, wurden produktive Mitglieder der Gesellschaft, heirateten und bekamen selbst Kinder (vgl. Brooks 2005: 95). Essenzielle Botschaft der Serie war „family unity, and the respect and reverence for the elders“ (Brooks 2005: 95), also gerade das, was in All in the Family definitiv nicht zu finden war.

Gegen Ende der 1970er Jahre erstarkte eine antiliberale und religiöse Bewegung in den USA, die u. a. eine Rückkehr zur Kernfamilie forderte und feministische Tendenzen als Bedrohung ansah (vgl. Dechert 2018: 59 f.). Dies zusammen mit der Präsidentschaft Ronald Reagans beendete die liberalen Tendenzen der 1970er Jahre.

\subsection{Die 1980er Jahre: Renormierung und normgerechte Diversifizierung}

Während die 1950er Jahre, die dem Fernsehen zu seinem Aufstieg verhalfen, gemeinhin als das ,golden age of television“ bezeichnet werden, gelten die 1980er und 1990er als das ",second golden age“ (vgl. Mittel 2003: 44). Mitte der 1980er Jahre wurde das Oligopol der drei großen Sender CBS, ABC und NBC, welches die zentralisierte Struktur des Fernsehens zuvor beherrscht hatte, durch den Aufstieg des Kabelfernsehens beendet (vgl. Rothemund 2013: 27). Kabelsender wie FOX produzierten zunehmend eigene Shows und vergrößerten somit massiv 
das Angebot auch an spezifischeren, weniger massentauglichen Formaten. Zusätzlich wurden die Richtlinien für Fernsehsender dereguliert, um mehr Werbung in den Programmen zu ermöglichen, womit eine Lockerung der Zensurbestimmungen einherging (vgl. Morreale 2003: 209). All diese Faktoren waren maßgeblich für die spätere Entwicklung des Fernsehens in eine zunehmend gesellschaftskritische Richtung. ${ }^{25}$ Vor der sukzessiven Lockerung der inhaltlichen Strukturen gegen Ende des Jahrzehnts kehrte das TV-Programm zu Beginn der 1980er dem experimentellen Realismus der 1970er Jahre den Rücken. War die Zahl der Family-Sitcoms während des vorherigen Jahrzehnts zurückgegangen, nahm die Zahl entsprechender Serien in den 1980er Jahren explosionsartig zu, eine Konsequenz der ,Rückbesinnung ' auf konservative Werte bzw. des Versuchs, Familie als Brennpunkt dieses Konservatismus wieder zu reinstallieren (vgl. Leppert 2019: 5).

Zumindest augenscheinlich hatten bezüglich der familiären Strukturen sowie der Werte und Normen, für die die Charaktere einstanden, in den TV-Familien der 1980er Jahre deutliche Veränderungen im Vergleich zu den 1950er Jahren stattgefunden: Die Huxtable-Eltern in The Cosby Show, beide afroamerikanisch, waren Teil der Bürgerrechtsbewegung gewesen und die Eltern der Serie Family Ties (1982-1989) gehörten in ihrer Jugend der Hippiebewegung an. Die Vergangenheit wirkte sich auf die familiären Strukturen aus. Während die Eltern der 1950er Jahre ,wussten', was gut für ihre Kinder war, und die Hierarchien innerhalb der Familie eindeutig feststanden, wurden die Kinder nun zu größerer Unabhängigkeit erzogen. Das Familienleben war nicht mehr autoritär, sondern demokratisch strukturiert und vor allem die Eltern - Angehörige einer konservativ erzogenen Generation - lebten eine Toleranz, die sie in ihrer Jugend selbst vermissten und schließlich erkämpfen mussten (vgl. Kutulas 2016: 24 f.). Das Leben dieser Familien war indes keinesfalls unharmonisch. Zwar war die Interaktion von TV-Familien in den 1980er Jahren mehr auf offenen Konflikt ausgelegt, z. B. zwischen Kindern und Eltern, als in den 1960er Jahren - eine notwendige Konsequenz der innerfamiliären Liberalisierung -, vor allem aber äußerten die Familienmitglieder ihre Besorgnis umeinander, ihre Fürsorge und ihre Liebe wesentlich offener als zuvor (vgl. Robinson/Skill 2001: 142).

Daran wird deutlich, dass diese Serien den Veränderungen und Entwicklungen der 1970er Jahre zwar Rechnung trugen, generell aber eine Rückorientierung zu

${ }^{25}$ So wurden beispielsweise ,sexuelle Themen bis weit in 1980er Jahre hinein von Familienserien quasi vollständig ausgeklammert, obwohl damit verbundene Probleme und Konflikte (etwa in der Pubertät oder im Eheleben), aber etwa auch Aspekte wie Unfruchtbarkeit, Schwangerschaft oder Verhütung eigentlich ja zum familiären Alltag gehören“ (Schleich/Nesselhauf 2016: 58 f.). 
harmonischeren Weltbildern stattfand, welche auf dominante konservative Gesellschafsströmungen der Reagan-Ära zurückzuführen ist. Nimmt man The Cosby Show, eine der populärsten Serien der 1980er Jahre als Beispiel, wichen Dysfunktionalität, Familiendramen und problematische Themen der 1970er Jahre traditionellen amerikanischen Werten und leichter lösbaren familiären Konflikten. ${ }^{26}$ In einer Zeit, in der fast die Hälfte aller Ehen in Scheidung endeten, war das Leben der Familie Huxtable eine Reminiszenz an eine, einfachere' Zeit (vgl. Morreale 2003: 210). Ähnlich verhielt es sich in Family Ties, die von Ronald Reagan als seine Lieblingsserie bezeichnet wurde. Hier erzogen liberale Eltern ihre Kinder, welche sich - im Gegensatz zu ihren Eltern - aber wieder konservativeren Werten und Verhaltensweisen zuwandten, also eine Umkehrung des Generationenkonflikts der 1970er Jahre (vgl. Brooks 2005: 138). Im Kern waren diese Serien somit identisch mit den Idealbildern der 1950er ${ }^{27}$ :

These texts are nearly identical to their 1950's predecessors, stressing the omnipotence of the father, the strength of the family unit, and the importance granted holidays, birthdays, and even simple family suppers. On television, Mother has been given a job and a more defined position in her children's emotional lives, but close analysis reveals that there is still consistently more structural and emotional power granted to the father (he has the right answer, he gets the funniest lines). (Leibman 1995: 263)

Die Zahl der berufstätigen Frauen im TV der 1980er (und 1990er) Jahre nahm, einhergehend mit realen Entwicklungen, weiter zu. Generell traten vielfältigere Frauenrollen auf. Um zugleich den konservativen Werten gerecht zu werden und werktätigen Frauen Identifikationspotenzial zu bieten, mussten die Serien der Zeit einen Spagat wagen (vgl. Leppert 2019: 1, 26). Bei der Darstellung alleinerziehender Frauen wurde stets darauf geachtet, die Vereinbarkeit von Beruf und Familie im Leben der dargestellten Mütter zu zeigen, auch um diese als Gegenmodell zu

\footnotetext{
${ }^{26}$ Einschränkend muss hervorgehoben werden, dass Cosby bereits zuvor als Komiker aktiv gewesen war und sich eine gewisse Popularität aufgebaut hatte, von der die Serie profitierte. Die späteren Skandale um den Hauptdarsteller Bill Cosby kontrastieren das Image Heathcliff Huxtables als liebenden Familienvater auf radikale Weise: 2018 musste Cosby eine Haftstrafe wegen der sexuellen Nötigung dreier Frauen antreten. 60 Frauen hatten ihn zuvor ähnlicher Vergehen beschuldigt (vgl. Kurier.at 2018). u. a. wurde er beschuldigt, seine Opfer unter Drogen gesetzt und vergewaltigt zu haben. Die Vorwürfe reichen dabei bis in die 1960er Jahre zurück (vgl. Pitzke 2014, vgl. Malone 2015).

${ }^{27}$ Interessant ist auch die Serie ALF (1986-1990), in der ein Außerirdischer Teil einer Familie wird. Die Familie ist mit dem Vater als Familienoberhaupt und alleinigem Geldverdiener, einem Haus in den Suburbs und zwei (später drei) Kindern traditionell strukturiert. Das Format verweist durch den Außerirdischen als fantastischem Charakter auf die eskapistischen Formate der 1960er Jahre.
} 
negativ besetzten Karrierefrauen zu etablieren (vgl. Leppert 2019: 8, 16). Um das Gesamtbild zu vervollständigen, wurden Väter, domestiziert' und vermehrt in den Haushalt miteinbezogen. Eine gemeinsame, gleichberechtigte Haushaltsführung war Teil eines romantisierten Gesamtbildes (vgl. Leppert 2019: 29, 58). Die erzieherische Rolle der Frau in der Familie wurde dabei weiterhin hervorgehoben. So wurde Claire Huxtable nur selten in ihrer beruflichen Position gezeigt und schien viel Zeit zu haben, sich um den Haushalt zu kümmern (vgl. Heintz-Knowles 2001: 178).

Die Darstellung geschiedener alleinerziehender Mütter nahm zwar sukzessive weiter $\mathrm{zu}$, wurde jedoch zumindest bis in die mittleren 1980er Jahre vorwiegend relativiert, indem männliche Verwandte oder Freunde in der Handlung neben den Protagonistinnen in den Vordergrund gerückt und als „symbolische Patriarchen“ präsentiert wurden.

(Dechert 2018: 65)

Indes betteten Serien wie Full House (198728-1995) alleinerziehende Väter zwar sozial ein, heroisierten aber deren alleinige Fürsorge um die Familie auf eine Art und Weise, die eine mütterliche Beteiligung redundant erscheinen ließ (vgl. Dechert 2018: 65 f.). Auch auf zuvor als integral weiblich gedachtem Territorium wurde also männliche Überlegenheit inszeniert. Obgleich alternative Modelle zur traditionellen Kernfamilie gezeigt wurden, blieben familiäre und Geschlechter-Hierarchien letztlich ,intakt ${ }^{\circ}$ bzw. orientierten sich an traditionell gedachten Strukturen. Im Weltmodell dieser Formate war es für eine Frau legitim zu arbeiten, solange sie ihre integral weibliche häusliche Rolle ausfüllte (vgl. Kutulas 1998: 25).

Neben der Huxtable-Familie als Ideal der Kernfamilie tauchten durchaus andere Familienmodelle auf: Die Familie Loudon in Newhart (1982-1990) hatte keine Kinder und in Webster (1983-1989) wurde ein schwarzer Junge von WeiBen adoptiert. Vor allem gegen Ende der 1980er wurde die Definition von Familie zunehmend weiter gefasst (vgl. Morreale 2003: 210). Während Prime-Time-Serien weiter konservative Familienmodelle stärkten, waren experimentelle und diverse Interpretationen zwar vorhanden, verloren allerdings durch eine Kopplung an konservative Werte und eine tendenziell komische Darstellung den potenziell bedrohlichen Charakter (vgl. Robinson/Skill 2001: 142).

\footnotetext{
${ }^{28}$ Im selben Jahr erschien auch der Film Three Men and a Baby, in dem sich drei erwachsene Männer um ein Baby kümmern mussten. Der alleinerziehende Vater wurde also zur wiederkehrenden Figur.
} 
Yet, even the ,aberrant" families were still defined by the norm of the middle-class nuclear family. All of these shows promoted the idea that family cohesion and unity would help individuals overcome obstacles, an idea that has permeated sitcoms throughout their history. (Morreale 2003: 210f.)

Seifenopern bzw. Soap-Operas, die mit Dallas (USA, 1978-1991) als ,erste große Prime-Time-Soap-Opera“ (Blanchet 2011: 39) einen großen Aufschwung erlebten, entziehen sich dem direkten Vergleich mit Sitcoms. Gemäß der dramatischen Prämisse, die der Bezeichnung „Opera“ inhärent ist, war die Handlung hier nicht von einer heilen Welt, sondern von dramatischen Konflikten gekennzeichnet. Ebenso wie die Familie Carrington in Dynasty (USA, 1981-1989) entsprach die Familie Ewing (Dallas) keinesfalls der mittelständischen Harmonie der Huxtables, sondern war von Untreue, Inzest, Vergewaltigung, Alkoholismus und ähnlichen Problematiken geprägt, die sie klar als dysfunktional kennzeichneten. Das Leben der Charaktere, die als Beispiele für menschliche Makel und Schwächen gelten konnten, war von Intrigen und komplexen Handlungslinien gekennzeichnet (vgl. Lichter et al. 1994: 156). Aufgrund ihrer Verortung in der Oberschicht und einer damit deutlichen Distanz zur Mehrzahl der Zuschauenden kommunizierte die Serie keinen Anspruch auf Darstellung eines allgemeingültigen US-amerikanischen Familienlebens (vgl. Books 2005: 5). Diese Soaps waren nur insofern vergleichbar mit Serien wie The Cosby Show, da sie keine nennenswerte Welt außerhalb der familiären Verbände zeigten (vgl. Lichter et al. 1994: 156) und Handlung sowie Probleme sich auf die Familie selbst und assoziierte Charaktere beschränkten.

Der große Erfolg von Serien wie The Cosby Show trug trotzdem nicht dazu bei, dass in den 1980ern vermehrt Serien mit afroamerikanischen Protagonist/inn/en ausgestrahlt wurden (vgl. Dates/Stroman 2001: 209). Mit Ronald Reagan und dem simplifizierenden „,race doesn't matter narrative“ endete David Leonard und Lisa Guerrero zufolge das "golden age of black television“ (Leonard/Guerrero 2013: 3). Kennzeichnenderweise wurde der erste Entwurf, der die Familie Huxtable in The Cosby Show als Familie der Arbeiterklasse zeigen sollte, abgelehnt (vgl. Brooks 2005: 144). Erst mit den Eltern in den Berufen des Arztes und der Anwältin - als Teil der gehobenen Mittelklasse - wurden sie schließlich in das Programm von ABC aufgenommen. Zwar war ,ethnic pride“ ein Teil des Lebens der Familie, er wurde aber nicht aggressiv verbreitet (vgl. Brooks 2005: 144). ,[The] Huxtables are initially constructed as little more than an average suburban family, who just happen to be African Americans“ (Leonard 2013: 115). Die afroamerikanische Abstammung ist also eher Zufall und nicht kennzeichnender Bestandteil des Lebens der Familie. Wie The Cosby Show marginalisierten 
die meisten Familiendarstellungen Ethnien- und Klassenunterschiede oder ignorierten diese, während es sich bei der Mehrheit um weiße Mittelklassefamilien handelte (vgl. Leppert 2019: 3). Zwar wurden so mit Klischees der afroamerikanischen Familie gebrochen, demgegenüber aber auch der „Blick auf die sozialen Missstände“" (Dechert 2018: 110 f.) im realen Leben verstellt.

$\mathrm{Zu}$ Beginn des Jahrzehnts wurden von konservativ-religiöser Seite heftige Ressentiments gegen Homosexualität und deren positive Darstellung in den Medien geschürt (vgl. Dechert 2018: 63 f.). Love Sydney (1981-1983) war im TVProgramm eine Ausnahme: Die Serie drehte sich um einen homosexuellen Mann, der ,eine alleinerziehende Mutter bei sich aufnahm und für deren Tochter zu einer Vaterfigur wurde“ (Dechert 2018: 66), womit sie gemeinsam eine Familie bildeten. Obgleich betont wurde, dass die Homosexualität des Protagonisten keine zentrale Rolle spielen würde, ging der Serie eine rege Diskussion voraus, in der von religiöser Seite scharfe Kritik und die Forderung nach Nicht-Ausstrahlung laut wurden (vgl. Dechert 2018: 68). Trotz ihrer relativ kurzen Laufzeit und heute geringen Bekanntheit war die Serie insofern bedeutsam, da sie ,das Kernfamilienideal [...] für homosexuelle US-Amerikaner“ öffnete, während zuvor „Homosexualität und Familie in weiten Teilen der US-amerikanischen Gesellschaft als unvereinbare Konzepte gedacht worden“" waren (vgl. Dechert 2018: 106). Love Sydney war ein früher Vorläufer der vermehrten Repräsentation von Familien mit homosexuellen Elternteilen nach der Jahrtausendwende.

Die 1980er Jahre festigten also gewisse Entwicklungen der 1970er Jahre, wie die Demokratisierung der Familie und die zunehmende Gleichberechtigung der Geschlechter. Die Integration dieser Werte in die Mittelklasse ebenso wie die Integration schwarzer Charaktere lassen sich durchaus als Fortschritt verstehen. Bezüglich des Konfliktpotenzials fand allerdings eine Rückwendung zu den moralischen Idealen und der Konfliktvermeidung der 1950er Jahre statt.

\subsection{Die 1990er Jahre: Satire und Dekonstruktion}

Angesichts der ,zunehmenden Vielfältigkeit der Familienformen“ verlor das „Ideal der Kernfamilie“ in den 1990er Jahren an Absolutheit (vgl. Dechert 2018: 5) und sah sich auf medialem Terrain der Kritik und der Parodie ausgesetzt. Bereits 1989 hatte mit Roseanne die Ausstrahlung einer Sitcom begonnen, die im Unterschied zur vorher dominanten weißen Mittelklasse-Familie das Leben der Arbeiterklasse-Familie Conner nachvollzog. Dieses war gezeichnet von ,conflict, struggle and pain“ (Morreale 2003: 247). Alle Rückschläge wurden indes mit Humor überwunden. Die Show widersetzte sich vielen Stereotypen der 
Sitcom-Mutter und dem langjährigen Trend konfliktarmer Unterhaltung. Wiederholt wurden kontroverse Themen angesprochen (vgl. Morreale 2003: 247). Bei der Protagonistin Roseanne handelte es sich um einen starken weiblichen Charakter, der sich patriarchalen Strukturen erwehren konnte, damit anderen Charakteren in der Serie ein Vorbild war und dem es zudem noch gelang, die Rolle als Ehefrau und Mutter einzunehmen (vgl. Leppert 2019: 140).

Ebenso wie die Conners war die Familie Bundy in der FOX-Sitcom Married... with Children (1987-1997) eine Familie der Arbeiterklasse. Im Gegensatz zu den Conners handelte es sich allerdings nicht um eine funktionale oder gar liebende Familie, sondern um eine Familie, die gerade durch ihre Dysfunktionalität definiert wurde (vgl. Morreale 2003: 247). Die Serie war explizit als Parodie auf die vorangegangenen Idealdarstellungen von Familien konzipiert ${ }^{29}$ und trug den Arbeitstitel Not the Cosbys. Familienvater Al war ein Chauvinist, der zahlreiche negative männliche Klischees erfüllte. Seine Ehefrau Peggy war eine unbeholfene, faule Hausfrau und die Tochter Kelly war dümmlich, attraktiv und stark auf ihre Sexualität bezogen. Der Sohn Bud, das intelligenteste Mitglied der Familie, befand sich im ständigen Streit mit seiner Schwester. Die Familie empfand keine besondere Zuneigung füreinander, sondern erfreute sich eher an den Missgeschicken der anderen (vgl. Brooks 2005:166).

Married...with Children ebnete den Weg für eine Serie, die 1989 zum ersten Mal ausgestrahlt wurde und die das Familienbild der kommenden Jahre massiv beeinflussen sollte: Matt Groenings Zeichentricksitcom The Simpsons, eine der erfolgreichsten Serien aller Zeiten, brachte einen ,heftigen Umschwung - hin zu einer Kritik, ja sogar einer Dekonstruktion der idealisierten Sitcom-Familie" mit sich (Kelsch 2019: 32). Die unbeschönigte Dysfunktionalität der Familie Simpsons stand im Kontrast zu den funktionalen Familien der 1980er (und 1950er) Jahre: Der Vater Homer ist ein fauler, beschränkter und narzisstischer Alkoholiker (vgl. Kelsch 2019: 32), die Mutter Marge muss unter der Unfähigkeit ihres Mannes leiden und keines der Kinder ist mustergültig (vgl. Kelsch 2019: 118). Der größte Unterschied zu der Konfliktscheue der vorangegangenen 1980er Jahre ist aber die umfassende Kritik der Serie, die alle Bereiche des Lebens, sowohl familiär und gesellschaftlich als auch politisch, miteinschließt. Weder Sexismus, Rassismus, Konsumwut, religiöser Fundamentalismus noch Homophobie bleiben von den satirischen Angriffen der Serie verschont (vgl. Kelsch 2019: 32, vgl.

${ }^{29}$ Diese parodistische Tendenz wird bereits durch das Intro der Serie deutlich, in dem Szenen aus dem desolaten Familienleben der Bundys mit dem Song „Love and Marriage“ (1955) von Frank Sinatra unterlegt werden, der „Liebe und Ehe“ als unverzichtbare Einheit darstellt. Damit nimmt Married... with Children direkt Bezug auf das Familienideal der 1950er Jahre. 
Henry 2012: 38). Vor allem zeichneten sich The Simpsons durch ihre starke populärkulturelle Einbettung durch intertextuelle Anspielungen aus, die auch andere Serien aufgriffen (vgl. Morreale 2019: 249). Trotz aller Kritik, so muss betont werden, sind The Simpsons weniger subversiv oder, gefährlich“ in Bezug auf die Familie als gesellschaftlichem Grundwert, als es den Anschein hat. Letztlich wird die Bedeutung der Familie stets aufs Neue betont und gefestigt (vgl. Kelsch 2019: 144, vgl. Henry 2012: 207).

The Simpsons waren vor allem prägend für die Zeichentricksitcom, die seither eine sehr eigene und überspitzt-satirische Form des Umgangs mit Familie und gesellschaftlichen Werten gefunden hat (vgl. Kelsch 2019: 147 ff.). Dennoch standen sie exemplarisch für den Kurs, den Kabelsender wie FOX Ende der 1980er/Anfang der 1990er Jahre einschlugen. Die größere Auswahl an Sendern und somit an Serien führte zunehmend zu einer Dezentralisierung des Publikums. Sender wie FOX versuchten mit Spartenprogrammen junge, zynische Zuschauende für sich zu gewinnen (vgl. Morreale 2003: 247) - auch die Intertextualität dieser Formate stärkte sicherlich die Attraktivität für diese Gruppe.

Die populärsten Family-Sitcoms des Jahrzehnts - wie Roseanne, Family Matters (1989-1997) und Home Improvement (1991-1999) - wurden nach wie vor vom großen Sender ABC produziert. NBC versuchte mit Serien wie Seinfeld (1990-1998), Frasier (1993-2004) und Friends (1994-2004), welche junge, weiße, unverheiratete und urbane Charaktere zeigte, ebenfalls ein jüngeres Publikum anzusprechen. Kennzeichnend für Seinfeld und vor allem - hier bereits im Titel deutlich - Friends ist, dass der Freundeskreis die Position der Familie einnahm.

Bei zahlreichen TV-Familien der 1990er Jahre handelte es sich entweder um Wahlverbände wie in Friends oder um konfliktreiche oder gar dysfunktionale Kernfamilien. Alternative, zuvor problematische Familienmodelle oder Charaktere waren nun keine Seltenheit mehr. Vermehrt traten geschiedene Eltern im Fernsehen auf (vgl. Robinson/Skill 2001: 158). Der Sitcom-Charakter Ellen in der gleichnamigen Sitcom (1994-1998) war sogar der erste Charakter einer populären Serie, der sich offen als homosexuell outete (vgl. Morreale 2003: 248 f.).

Auch traditionelle Familienmodelle waren mit Serien wie Home Improvement, eine Rückkehr zur Kernfamilie der 1950er Jahre (vgl. Brooks 2005: 189), nach wie vor vorhanden. Obwohl der Glaube des Familienvaters Tim Taylor an maskuline Selbstfindung Grundlage für Gags war, bemühte er sich doch - im Gegensatz zu seinen Gegenstücken der Arbeiterklasse - ein guter Vater zu sein. Vor allem sorgte sich die Familie in ihrer Gesamtheit um ein funktionierendes Familienleben (vgl. Dechert 2012: 287). 
Trotz starker weiblicher Charaktere sorgten Frauenrollen besonders zu Beginn der 1990er Jahre weiter für Gesprächsstoff. Der republikanische Vizepräsident Dan Quayle kritisierte den TV-Charakter Murphy Brown, eine Anwältin aus der gleichnamigen Sitcom (1988-1997, 2018), für ihre Entscheidung, ihr Kind ohne Vater aufzuziehen (vgl. Dechert 2012: 160).

Mit der Darstellung einer weißen, beruflich erfolgreichen Frau, deren Rolle als zumindest nominell alleinerziehende Mutter weder mit der Zugehörigkeit zu einer pathologisierten Minderheit noch mit mangelnder Bildung und Intelligenz ,erklärt` werden konnte, hatte die Sitcom vor allem in den Augen konservativer US-AmerikanerInnen einen Tabubruch begangen. (Dechert 2012: 158)

Alleinerziehende Mütter in Serien waren zu Beginn der 1990er Jahre absolut keine Seltenheit mehr, hatten aber ,wenn überhaupt - nur bedingt ihr Stigma verloren“ (Dechert 2012: 198). Obwohl der Vater des Kindes sich in der Serie bewusst gegen die Übernahme der Vaterschaft entschieden hatte, galt Murphy Brown für konservative Kritiker/inne/n als „Verkörperung einer selbstsüchtigen Frau, die ihren Wunsch nach einem Kind ungeachtet von dessen Bedürfnissen zu verwirklichen suchte“ (Dechert 2012: 198). Noch 1998 schreibt Kutulas:

Television both echoes and contributes to a female experience where pervasive social guilt about never being good enough turns liberation back onto women and makes its limitations their fault. (Kutulas 1998: 30)

Während durchaus starke weibliche Charaktere auftraten, waren viele Aspekte emanzipierter Weiblichkeit, in Hinblick auf Vorstellungen von Mütterlichkeit und Häuslichkeit, noch weit bis in die 1990er Jahre hinein mit Schuld beladen. Auch Sex and the City (1998-2004) fokussierte sich auf weibliche Charaktere, zeigte aber ein stark idealisiertes, feminisiertes und heteronormatives Bild von Weiblichkeit (vgl. Guerrero 2013: 179).

Hinsichtlich der Darstellung afroamerikanischer Charaktere im TV brachten die 1990er Jahre ebenfalls Veränderungen mit sich. Anfang der 1990er Jahre versuchte insbesondere FOX das stiefmütterlich behandelte afroamerikanische Publikum mit Serien wie In Living Color (1990-1994), Martin (1992-1997) und The Sinbad Show (1993-1994) anzusprechen (vgl. Perren 2003: 109). Auch die großen Sender begannen populäre Programme mit afroamerikanischer Besetzung wie The Fresh Prince of Bel-Air (1990-1996) oder das bereits erwähnte Family Matters zu produzieren. Beide Serien sparten dabei Fragen der Ethnie und afroamerikanischer Identität nicht mehr aus wie zuvor, sondern setzten sich mit 
entsprechenden Problematiken auseinander (vgl. Patterson 2013: 166). Die Stellung von Personen afroamerikanischer Abstammung im Fernsehen blieb jedoch allgemein problematisch, sicherlich auch deswegen, weil Ende der 1990er noch über $90 \%$ der Entscheidungstragenden der Medien-Industrie weiß (und männlich) waren. ${ }^{30}$ Vor allem aber wurden Personen afroamerikanischer Abstammung, in den 1990ern wie zuvor auch, meist in komischen Formaten gezeigt, die unterhalten und nicht zum Nachdenken anregen sollten (vgl. Dates/Stroman 2001: 211). Die Darstellung von Personen afroamerikanischer Abstammung als Karikaturen, welche ebenso in den 1990er Jahren kein Ende fand, trug zu einer problematischen (Selbst-)Wahrnehmung der Bevölkerungsgruppe bei (vgl. Dates/Stroman 2001: 215). Andere US-amerikanische Minderheiten blieben weiterhin vollkommen vernachlässigt: Lateinamerikanische Menschen traten in vornehmlich stereotypen Rollen auf und wurden - deutlich häufiger als Weiße - als kriminell dargestellt (vgl. Dates/Stroman 2001: 219). In geringem Maße und ebenso wenig vorteilhaft wurde die nordamerikanische, indigene Bevölkerung, d. h. ,native americans ", repräsentiert. Meist wurden sie als alkoholkrank, arm, familienorientiert, aber mit dysfunktionalen Familien abgebildet. Genauso wenig umfangreich, dafür umso stärker stereotypenbelastet war die Darstellung anderer Minderheiten wie Personen asiatischer Herkunft (vgl. Dates/Stroman 2001: 220). ${ }^{31}$ Dates und Stroman charakterisieren die Darstellung von Minderheiten in den 1990er Jahren wie folgt:

The social realities of African Americans, Asian Americans, Native Americans and Latinos families are still not portrayed accurately; rather, their portrayals reflect the myopic lens through which people of color are viewed by decision makers in the television industry. (Dates/Stroman 2001: 220)

Obwohl die 1990er Jahre eine Umbruchphase darstellten und zu einer deutlichen Diversifizierung des dargestellten Gesellschaftsbildes beitrugen, blieben Stereotype und Benachteiligungen in Quantität und Qualität der Repräsentation nicht weißer Charaktere erhalten und setzen sich bis heute fort. Über einen verstärkt satirischen Umgang mit dem Konzept der traditionellen Kernfamilie übten Serien

\footnotetext{
${ }^{30}$ Janette Dates und Carolyn Stroman verweisen auf eine Beobachtung des Los Angeles TimesKritikers Greg Braxton aus dem Jahre 1997, nachdem Formate, die von Weißen am positivsten bewertet wurden, einen ausschließlich weißen ,core cast“ hatten, die von Personen afroamerikanischer Abstammung am positiv bewerteten Formate indes einen afroamerikanischen. Es fand also eine Art Ghettoisierung innerhalb der Fernsehlandschaft statt (vgl. Dates/Stroman 2001: 210).

${ }^{31}$ Die Sitcom All-American Girl (ABC, 1994-1995) war die erste US-amerikanische Serie, die eine koreanisch-amerikanische Familie abbildete (vgl. Brooks 2005: 6).
} 
- implizit oder explizit - Kritik an gesellschaftlichen Strukturen. Allerdings blieb die Familie weiterhin ein positiv besetzter Raum und gewisse konservative Vorstellungen bezüglich familiärer Rollenverteilung und insbesondere bezüglich ,weiblicher Aufgaben“ wurden zwar kritisiert, blieben aber bestehen.

\subsection{Die 2000er und Tendenzen des 21. Jahrhunderts: Restabilisierung, Dekonstruktion und gestiegene Komplexität}

Über die Entwicklungen und Familiendarstellung der 2000er zu sprechen, ist aufgrund der geringen zeitlichen Distanz nicht unproblematisch. Eine umfassende Einordnung wie die der vorangegangenen Jahrzehnte ist nicht ohne Weiteres möglich. Dennoch lassen sich bereits gewisse Schlüsse ziehen.

Die 2000er weisen gegenläufige Strömungen auf. Einerseits - ähnlich wie in den 1980er Jahren - lassen sich restabilisierende Tendenzen feststellen, vermutlich auch als Reaktion auf die Anschläge vom 11. September 2001 und aus einem daraus folgenden Bedürfnis nach Sicherheit unter der Regierung George Bushs (vgl. Morreale 2003: 250). Das ist bei einem Blick auf die Entwicklung der Serie nachvollziehbar. Diese fand ihren Anfang mit einer Normsetzung und Strukturfindung in den 1950er Jahren und weist, stark abhängig von der politischen, sozialen und gesellschaftlichen Lage, sowohl progressive (die 1970er und 1990er Jahre) als auch rückwärtsgerichtete Phasen (die 1960er und 1980er Jahre) auf. ${ }^{32}$ Stabilisierende und konservative Tendenzen, wie sie während den von Krieg und wirtschaftlicher Depression bestimmten 1950er Jahren und dem Konservatismus der Ära Reagan/Bush sen. in den 1980er Jahren stattfanden, legen während der Ära Bush jun. - Afghanistankrieg, Irakkrieg und aufkeimende Terrorangst - eine Rückbesinnung auf als Tradition gedachte Werte nahe. Dennoch ist zu beobachten, dass Entwicklungen nie ohne Spuren bleiben, also niemals vollkommen revidiert werden. Ändern sich also auch gewisse Norm- und Wertsetzungen nicht,

\footnotetext{
${ }^{32}$ Wie bereits erwähnt sind die aufgezeigten Charakteristika der Jahrzehnte nicht als absolut zu verstehen, sondern verweisen auf dominante bzw. markante Entwicklungen innerhalb eines bestimmten Zeitraums. Stets gab es auch Serien, die den beschriebenen Entwicklungen entgegenliefen, wie das eher konservative Bonanza, das bis 1973 im Fernsehen lief, oder die traditionelle Familienvision der Waltons, die sich in den Jahren 1972 bis 1981 großer Beliebtheit erfreute. In keinem Fall soll der Eindruck erweckt werden, die mediale Entwicklung sei ein einsträngiger Prozess. Vielmehr handelt es sich um eine Entwicklung, die zahlreiche, teils gegenläufige Strömungen umfasst und die sich mit dem Wechsel eines Jahrzehnts zum anderen nicht schlagartig ändert.
} 
so bleiben bestimmte ,Fortschritte' doch erhalten. Dies lässt sich am Beispiel der 1980er Jahre belegen, während denen zwar eine Rückkehr zu einer möglichst konfliktarmen medialen Repräsentation der Familie stattfand, die Familien und Geschlechterrollen aber deutlich egalitärer konzipiert waren. Trotz stabilisierender Tendenzen wurden die bekannten Stereotypen der harmonischen ,all-American television family“ umfassend dekonstruiert (vgl. Brooks 2005: 213), eine vollständige Rückkehr zum Bild der 1950er oder der 1980er Jahre ist unter den gegebenen Bedingungen unwahrscheinlich.

Auffällig ist, dass einige der populärsten Sitcoms der 2000er und 2010er Jahre wie How I Met Your Mother (2005-2014), Scrubs (2001-2009) oder The Big Bang Theory (2007-2019) einen Trend der 1990er Jahre fortsetzen und keine genetischen, sondern Wahlfamilien, also Gruppen aus befreundeten Menschen oder Kolleg/inn/en, welche sich anfreunden, zeigen. All diesen Serien ist indes gemein, dass die Charaktere, ebenso wie in Friends, die anfangs noch ein ungebundenes jugendliches Leben führen, letztlich Familien gründen, d. h. heiraten, Kinder bekommen, einen gefestigten Job haben und sich räumlich - eine eigene Wohnung oder ein Haus - aus dem Freundschaftsverband lösen. Diese Loslösung von der Wahlfamilie und die Hinwendung zu einer endgültigen und dauerhaften Familie bestätigt die konservative Norm der Kernfamilie. Sie stellt für die Charaktere den Endpunkt der in der Serie gezeigten Entwicklung dar. Sie symbolisiert das Ende der Jugend und - unabhängig vom Alter der Charaktere - den Beginn des Erwachsenenalters und damit des ,ernsthaften Lebens'. Anderen Serien, die weiterhin die Familie in den Mittelpunkt stellten, z. B. Malcolm in the Middle (2000-2006) oder Two and a Half Men (2003-2015), zeigen einerseits dysfunktionale Verhältnisse und betonen andererseits die Bedeutung familiären Zusammenhalts. ${ }^{33}$ Auch in Serien wie The Sopranos (1999-2007), in der ein Mafiaboss ein Doppelleben als

\footnotetext{
332003 stellt William Douglas fest, dass die US-amerikanische Kernfamilie weiterhin isoliert von der Gesellschaft in Suburbs dargestellt werde (vgl. Douglas 2003: 111 f.). Diese Verlagerung in eine Vorstadt bleibt auch in Darstellungen von dysfunktionalen Familien der 2000er Jahre wie z. B. Malcolm in the Middle (2000-2006) oder einer Vielzahl von kritischen Zeichentricksitcoms erhalten. Wenn in diesen Serien auch häufig, Ausflüge ' an andere Schauplätze unternommen werden, ist das wiederkehrende Zentrum bzw. der Start- und Endpunkt des Geschehens doch meist das gemeinsame vorstädtische Haus. Probleme werden nach wie vor in der Familie und größtenteils ohne gesellschaftliche oder institutionelle Intervention, gelöst‘. Es ist fraglich, inwieweit diese Bindung an die Vorstädte als ideologisch zu bewerten ist, wenn explizit keine funktionalen Familien mehr gezeigt werden. Vielmehr ist der wiederkehrende Handlungsort der Narration geschuldet. Ein wiederkehrender Ort sowie eine Konfliktlösung innerhalb des familiären Gefüges erlauben eine engere Bindung an die Protagonist/inn/en. Zudem entspricht ein Leben in den Vorstädten der Lebensrealität vieler Menschen in den USA und bietet somit Identifikationspotenzial.
} 
Familienvater und Mafioso führt, die eindeutig problematische Familiendynamiken aufzeigt und zudem noch explizite Darstellungen von Gewalt und Nacktheit enthält, wird Familie nach wie vor zentral thematisiert und steht im Mittelpunkt des Handelns des Protagonisten (vgl. Brooks 2005: 210). Inhalt und Darstellungsweisen der Serie können dem zentralen Ideal wenig anhaben. Gewissermaßen stellt sie sich mit dem Titel, der an zahlreiche Serien erinnert, welche nach einer Familie benannt sind, deutlich in die Tradition der Familienserie.

$\mathrm{Zu}$ Beginn der 2000er Jahre stellt Erica Scharrer eine signifikant gestiegene Zahl von Scherzen fest, die Sitcom-Mütter auf Kosten ihrer Ehemänner machen. Gleichzeitig übersteigt deren Anzahl die gegenläufigen Scherze (von Vätern auf Kosten der Mütter). Hieraus leitet Scharrer eine erhöhte Machtposition der Frauen ab (vgl. Scharrer 2001: 36). Allgemein fällt bezüglich der Rolle der Frau auf, dass die konservative politische Agenda für eine tendenzielle Rückwendung gesorgt hat (vgl. Henry 2012: 106), während zeitgleich progressive Darstellungsformen existieren:

[T]raditional and progressive ideologies of 'femininity' and 'womanhood' exist simultaneously, in both the mass media and the culture itself, and at this particular moment in American history, they remain in conflict. (Henry 2012: 107)

Selbst konservative Darstellungen von Weiblichkeit gleichen sich nicht der Darstellung der 1950er Jahre an. Allgemein, so Douglas, seien Ehen im Fernsehen zwar konfliktreicher geworden und die Eheleute weniger im Stande mit dem familiären Leben zurechtzukommen als ihre Vorgänger, es werde jedoch auch mehr Zuneigung und Unterstützung gezeigt als zuvor, dies lasse auf einen komplexeren emotionalen Kontext schließen (vgl. Douglas 2003: 112).

Trotz einer beobachtbaren Rückwendung - und dies begründet meine These einer Dekonstruktion - brachten die 2000er Jahre eine Vielzahl aggressiv kritischer Formate mit sich, wie sie zuvor in dieser Form niemals entsprechend prominent existierten. Vor allem Zeichentricksitcoms wie American Dad! (seit 2005), Family Guy (seit 1999) oder South Park (seit 1997) bauen auf dem Erfolg von The Simpsons auf, üben systematische Gesellschaftskritik (vgl. Kelsch 2019: 144) und nehmen eine Dekonstruktion überhöhter Familienmythen vor (vgl. Kelsch 2019: 142). ${ }^{34}$ Die hier dargestellten Familien sind von unfähigen

\footnotetext{
34 Bereits vor den populären Zeichentricksitcoms, die im Kielwasser von The Simpsons entstanden, existierten ähnliche Programme, also Zeichentrickserien für Erwachsene wie Wait Till Your Father Gets Home (1972-1974), The Barkleys (1972-1973) oder Where's Huddles? (1970), die mit überzeichneten Charakteren gesellschaftliche Gegebenheiten karikierten. Das Genre der , adult animated sitcom " wurde also nicht durch The Simpsons erfunden. Allerdings
} 
Tyrannen regierte Zwangsstrukturen, unter deren Ausweglosigkeit die an Heim und Herd geketteten Ehefrauen ebenso wie die Kinder leiden müssen (vgl. Kelsch 2019: 143). Hemmungsloser Narzissmus und Egoismus und das unreflektierte Festhalten an Überzeugungen, die fast allen Figuren zu eigen sind, machen ein ,Ideal' von Familie, das enge soziale Beziehungen, persönliche und emotionale Bindungen als bedeutsam setzt, von Vornherein unmöglich (vgl. Kelsch 2019: 145). Das ,Gefängnis' Familie wird nur aus dem Grund nicht verlassen, da es Schutz vor einem chaotischen Außenraum bietet, in dem jeder seine Interessen ohne jede Rücksicht verfolgt: Es handelt sich um das ,kleinste Übel in einer Welt großer Übel“ (Kelsch 2019: 125, 145). Obgleich der Mythos der Idealfamilie und die damit einhergehenden Rollenmodelle in den Weltmodellen der Zeichentricksitcom offensichtlich nicht umsetzbar sind bzw. bei Anwendung destruktive Auswirkungen auf die Mitglieder der Gesellschaft haben, werden sie - ebenso wie bestimmte problematische Verhaltensweisen - von Generation zu Generation weitergegeben und sind somit vor Auflösung geschützt (vgl. Kelsch 2019: 143 f.). Es ist zu betonen, dass es sich bei Zeichentricksitcoms um satirische Formate handelt, deren Inhalte und Darstellungsweisen sicherlich nicht für die Gesamtheit aller Serien verallgemeinerbar sind. Sie weisen eigene Spezifika und Tendenzen auf. Dennoch liegt in Zeiten großer medialer Interdependenzen eine wechselseitige Beeinflussung bzw. eine Beeinflussung jüngerer Medienschaffender durch mittlerweile ,Kult' gewordene Serien nahe.

Die Darstellung von Personen afroamerikanischer Abstammung seit den 2000ern wird von Seiten der Forschung kritisch betrachtet. Hier liegt eine Ähnlichkeit zu den 1990er Jahren vor: Seit den Huxtables aus The Cosby Show gab es keine vergleichbar populäre Serie mit einer afroamerikanischen Familie (vgl. Douglas 2003: 154). Weiterhin ist der Einfluss von Personen afroamerikanischer Abstammung in Sendern und Produktionsfirmen recht gering, was zu einer fortgesetzten Darstellung entsprechender Charaktere als Stereotypen beiträgt (vgl. Cutts 2013: 204). Wenn das Publikum entsprechende Darstellungen weiterhin unterstütze, so Paula Groves Price, würden diese weiterhin Teil des Programms bleiben (vgl. Groves Price 2013: 440). ${ }^{35}$

war den vorangehenden Formaten weder entsprechender Erfolg oder Langlebigkeit beschieden, noch können sie aus heutiger Perspektive als entsprechend wirkmächtig gelten. In den 1990er Jahren nahm die Anzahl dieser Serien zudem sprunghaft zu.

35 Groves Price beklagt zudem die negative Darstellung von Personen afroamerikanischer Abstammung in Reality-Formaten: „Undoubtedly, the images found in the (black) reality genre today are dominated by classed images of black women as Sapphires or bitches and of black men as players and criminals. Portrayed as loud, aggressive, rude, confrontational, and lacking moral character, the controlling image of the bitch becomes a central feature 
Bezüglich alternativer Familienmodelle fand in den 2000er Jahren eine deutliche Entwicklung statt. Mit Serien wie Six Feet Under (2001-2005), Modern Family, Glee (2009-2015), Brothers and Sisters (2006-2011), The New Normal (2012-2013) und Orange Is the New Black (2013-2019) wurden vermehrt LGBTQ-Charaktere, vor allem gleichgeschlechtliche Paare und queere Familien, gezeigt (vgl. Young/McCrady 2018: 118, vgl. LeVay 2019: 105 f.). Auch Themen wie Leihmutterschaft fanden, z. B. in The New Normal, ihren Eingang in TVSerien (vgl. LeVay: 2019). Bei Familien liegt eine Zentrierung auf homosexuelle Vaterschaft vor, mehr als auf homosexuelle Mutterschaft (vgl. Young/McCrady 2018: 118). Auch nehmen unter den LGBTQ-Charakteren weiße homosexuelle Männer eine Mehrheit ein (vgl. LeVay 2019: 106). The Fosters (2013-2018) ist insofern ein herausstechendes Beispiel, da sich die Serie, welche ein lesbisches Ehepaar unterschiedlicher Ethnie mit ihren leiblichen und ihren Adoptivkindern zeigt, gezielt an ein Publikum im Teenager-Alter richtet (vgl. Young/McCrady 2018: 118). Die Tatsache, dass die Darstellung von LGBTQ-Charakteren das Erwachsenen-Fernsehen somit verlassen hat, zeigt, dass entsprechende Familienund Lebensmodelle langsam in den kulturellen Mainstream vordringen. Es sticht jedoch heraus, dass es sich bei den dargestellten alternativen Familien in der Regel um Modelle handelt, die heteronormativen Strukturen folgen (vgl. LeVay 2019: 105). Das heißt, dass gelungene Partnerschaften - egal ob homo- oder heterosexuell - letztlich einer klassischen monogamen Struktur folgen (vgl. LeVay 2019: xi). Auch streben die Charaktere meist nach einer ,queer straightness", also einer Angleichung an heterosexuelle Verhaltensweisen und Normen, sicherlich mit dem Ziel, Charaktere zu schaffen, die „less threatening to mainstream culture" sind, also konservativere Rezipierende nicht, überfordern“ (vgl. LeVay 2019: 128). Ebenso wird gleichgeschlechtliche Sexualität bzw. die sexuelle Verbundenheit der Pärchen nicht oder kaum dargestellt (vgl. LeVay 2019: 104). Mit dieser Angleichung und Normalisierung werden - ähnlich wie im Falle der Angleichung afroamerikanischer Familien, z. B. den Huxtables - reale Konflikte und Problematiken des homosexuellen Lebens ausgeblendet (vgl. Young/McCrady: 121, 133).

of understanding the breakdown and drama endemic to black relationships and families. Coupled with the dominant image of the black man as the player and criminal, unable to resist temptations of additional women, fast money, and playing, the raced and classed portrayals of black men and women become the opposite of white gender ideology" (vgl. Groves Price 2013: 440). Es liegt also weiterhin eine starke Negativinszenierung der afroamerikanischen Bevölkerungsgruppe von vor, die wiederum durch ihre starke mediale Verbreitung zu einem negativen Selbstbild der afroamerikanischen Gesellschaft beiträgt. 
Der Schlüssel für die Entwicklung der 2000er Jahre und vielleicht auch des folgenden Jahrzehnts sind die Stichworte Komplexität und Ambivalenz. Die Serien des vergangenen Jahrzehnts folgen weniger stereotypen oder eingefahrenen Strukturen, sondern orientieren sich an einem schattierungsreichen Weltbild. Diese erhöhte Komplexität ist sicherlich auch Produkt der Digitalisierung, die den Informationszugang erweitert und allgemein zugänglicher gemacht hat. Damit steigt die Zahl kritischerer Formate, die traditionelle Weltbilder parodieren oder in Frage stellen oder Alternativen zu diesen Weltbildern aufzeigen. Nichtsdestotrotz zeigt die Ausrichtung alternativer Modelle an hergebrachten Strukturen, dass über Jahrzehnte gefestigte Vorstellungen sich nicht plötzlich in Luft auflösen, sondern einem sukzessiven Erosions- oder Umformungsprozess unterliegen.

\subsection{Zwischen Harmonie und Dysfunktionalität: Die Linien der Familiendarstellung in Serien seit 1950}

Die Darstellung der Familie in US-amerikanischen Fernsehserien war seit 1950 deutlichen Veränderungen unterworfen. Diese Entwicklungen nachzuvollziehen, so wird bei einem Blick auf die vorangegangene Zeitlinie deutlich, heißt primär einen Wandel der Geschlechterrollen nachzuvollziehen. Diese erfuhren - einhergehend mit der gesellschaftlichen Entwicklung - eine deutliche Liberalisierung seit der extremen Einengung und Reduzierung weiblicher Charaktere auf ihre Hausfrauen- und Mutterrolle in den 1950er Jahren, die nicht nur auf die Mütter, sondern auch auf deren Töchter angewendet wurde. Die zunehmende Gleichstellung von Mann und Frau über die Jahrzehnte hinweg kann allerdings nicht darüber hinwegtäuschen, dass selbst in Serien mit emanzipierten und weitgehend eigenständigen Charakteren nach wie vor eine Identifikation mit der Mutter- und Hausfrauenrolle vorliegt. Ist ein Ehemann bzw. Vater vorhanden, übernimmt er häufig weiterhin die Position als Oberhaupt der Familie. Noch 1996 konstatieren Decker et al.:

Die Hierarchie dieses Modells ist das der patriarchalischen Führung, in dem der Vater als Autorität der Richter und Repräsentant des Wertesystems ist. Die Mutter ist ihm untergeordnet, was die Vertretung der Familie im außerfamiliären Raum betrifft. Sie übernimmt aber in der Rolle der Vermittlung des Wertesystems durch die Erziehung der Kinder eine zentrale Funktion im innerfamiliären Raum und ist dem Vater hier als Autorität beigeordnet. Die Kinder qualifizieren sich über das Erlernen des Modells durch Gehorsam und Vertrauen in die Führung der Eltern als wertvolle Menschen. Sie müssen sich der normsetzenden Instanz der Eltern unterordnen. (Decker et al. 1996: 76) 
Die Mutter bleibt also nach wie vor in den emotionalen Lebensbereichen und im innerfamiliären Raum verhaftet, welche sie als Schutzzone gegen das Äußere von innen pflegt und aufrechterhält. Der Vater versorgt die Familie auf materieller Ebene und vertritt und verteidigt diese im Außenbereich. Zudem gibt er grundlegende Werte der ,Männlichkeit' an potenzielle Söhne weiter, damit diese die Familie im ,Mannesstamm“ fortsetzen können (vgl. Decker et al. 1996: 79 f.). Diese Struktur wird selbst bei den genuin kritischen Zeichentricksitcoms aufrechterhalten, wenn auch nur um hier dekonstruiert zu werden.

Die berufliche und intellektuelle Verwirklichung, die weiblichen Charakteren lange Zeit verwehrt blieb, ist heute Normalität: Frauen sind in den vorliegenden Wertemodellen dazu legitimiert, sich zu bilden und einen Beruf auszuüben, wie sich vor allem in Serien der vergangenen 20 Jahre wie Scrubs, How I Met Your Mother oder The Big Bang Theory zeigt, in denen es zahlreiche weibliche Charaktere mit abgeschlossenem Studium und/oder gefestigtem Arbeitsplatz gibt. Dennoch wird die Bindung an Emotionalität und Fürsorglichkeit aufrechterhalten. Allein daran, dass die Initiative zur Paarbindung meist von den männlichen Charakteren ergriffen wird, zeigt sich weiterhin eine Dominanz des männlichen Parts.

Ein Aspekt, der bisher nicht angesprochen wurde, ist die Rolle der geschwisterlichen Beziehung in Serien. Mary Strom Larson vollzieht - in Bezug auf die Sitcom - die Entwicklung geschwisterlicher Bande bis in die (einschließlich) 1990er Jahre nach (vgl. Strom Larson 2001: 163 ff.). Während die Interaktion von Geschwistern in Sitcoms der 1950er Jahre deutlich positiv war und beispielsweise auf einer Vorbildfunktion älterer Geschwister für die jüngeren basierte (vgl. Strom Larson 2001: 165), nahm diese geschwisterliche Unterstützung in den 1960er Jahren ab und das Verhältnis wurde konfliktreicher. Zu den 1970er Jahren liegen Strom Larson nicht ausreichend Daten vor. Die 1980er Jahre stellen einen Höhepunkt negativen geschwisterlichen Verhaltens dar, auch wenn die Beziehungen weiterhin weitgehend positiv bleiben (vgl. Strom Larson 2001: 172). Die 1990er Jahre zeigen negative geschwisterliche Beziehungen ebenso wie positives, unterstützendes Verhalten (vgl. Strom Larson 2001: 174). Allgemein, so fasst Strom Larson zusammen, sei das Verhalten unter Geschwistern über die Jahrzehnte eher positiv dargestellt worden (vgl. Strom Larson 2001: 174). Die Ursache zunehmend kritischerer Darstellungen geschwisterlichen Verhaltens lässt sich in einer sukzessiven Deharmonisierung der Fernsehfamilien vermuten, welche Konfliktdarstellung zulässt. Wenige Beispiele liegen für eine Wertevermittlung unter Geschwistern bzw. eine gegenseitige Prägung des Verhaltens vor (vgl. Strom Larson 2001: 175). Dies erlaubt den Schluss, dass die Beziehungen zwischen Eltern und Kindern allgemein relevanter ist als die Beziehungen zwischen den Kindern. 
Die Eltern haben stets die Autorität in der Wertevermittlung und der zentralen Prägung ihrer Kinder inne. Dabei ist die „Mutter-Kind-Dyade [...] von höherem Wert als die Vater-Kind-Dyade und beides ist weniger wert als die Vater-MutterKind-Triade“ (Decker et al. 1996: 77). Die Rolle der Frau als Mutter ist also auch hier als dominant gesetzt. ${ }^{36}$

Betrachtet man die Entwicklung der Familie in ihrer Gesamtheit über die Jahrzehnte hinweg, so bleibt sie in ihrer zentralen Funktion konstant. Familie ist stets Schutzraum bzw. Zufluchtsraum gegenüber der ,realen“ Welt, also dem öffentlichen, nicht privaten Raum. Hier können die Kinder unter Anleitung der Eltern gefahrlos Verhaltensweisen einüben, während die Eltern Ruhe und Erholung von der Außenwelt finden. Dabei bleibt die Familie eine abgeschlossene Größe, also in ihrer letztlichen Problemlösungs- und Erziehungsfunktion unbeeinflusst von Staat und Gesellschaft. Das Eingreifen staatlicher Institutionen wird meist mehr als Störung denn als Hilfe wahrgenommen. Die scheinbare Lösung von persönlichen Problemen und potenzielle intergenerationelle Konflikte erlauben es, in der Familienserie in besonderem Maße relevante gesellschaftliche Paradigmen zu verhandeln.

Die genetische Familie wird dabei eindeutig höher bewertet als die Wahlfamilie. Das Leben im Freundschaftsverband ist stets nur eine Phase und wird einer, wirklichen' Familie zugeführt. Da das Leben in der Wahlfamilie bereits zu Beginn, durch die familiäre Selbstverwirklichung der Charaktere, auf ein Ende abzielt, kann es - in der Logik der Weltentwürfe - als defizient verstanden werden. Ein optimaler Zustand würde schließlich nicht beendet werden - entsprechend ist die Trennung von Fernseh-Kernfamilien nach wie vor selten. Alternative Familienmodelle, die nicht mit der traditionellen Kernfamilie übereinstimmen, tauchen zwar wiederholt auf, konnten aber weder medial noch gesellschaftlich einen ansatzweise vergleichbaren Status entwickeln wie die traditionelle Kernfamilie. Dies hat beispielsweise auch das Streben homosexueller Paare nach einer heteronormativen Norm zur Folge (vgl. Douglas 2003: 4). ${ }^{37}$ Dass die Familie als Schutzraum dient, ist dabei allerdings nicht Garant für deren Funktionalität oder

\footnotetext{
${ }^{36}$ Katharine Heintz-Knowles stellt 2001 fest, dass sich Arbeit und Familie in Serien selten überschneiden. Wenn dies der Fall ist, sind Probleme im Leben männlicher Charaktere meist familieninduziert, während die Probleme weiblicher Charaktere meist mit der Arbeit zusammenhängen. Dies weist auf die klassische Rollenverteilung hin, welche Frauen der Familie und Männer der Arbeitswelt zuordnet (vgl. Heintz-Knowles 2001: 197 f.).

${ }^{37}$ Dafna Lemish zeigt auf, dass Kinderserien nach wie vor die traditionelle Kernfamilie als Norm präsentieren sowie kaum alternative Modelle zeigen, und verweist darauf, dass dies eine negative Wirkung auf Kinder in abweichenden Familien habe, da diese sich nicht repräsentiert sehen (vgl. Lemish 2012: 153, 166). Zudem würden vorrangig Familien der Mittelschicht ohne finanzielle Probleme gezeigt (vgl. Lemish 2012: 155). Eine Vermittlung entsprechender
} 
Stabilität. Vielmehr zeigt sich durchaus eine Tendenz, neben weiterhin bestehenden funktionalen Familien - wie sie z. B. den Endpunkt der bereits genannten Freundschaftsverbände bilden - vermehrt dysfunktionale Familien, wie z. B. in Zeichentricksitcoms, darzustellen. ${ }^{38}$ Diese Verbände werden dabei einerseits durch den Mythos der Bedeutung bzw. Alternativlosigkeit von Familie aufrechterhalten, andererseits durch ihre Opposition zu einem noch dysfunktionaleren Außenraum.

Immer wieder wurde die Darstellung nicht weißer, insbesondere afroamerikanischer Familien hervorgehoben. Diese waren über die Jahrzehnte hinweg problematisch. Während Minderheiten neben Personen afroamerikanischer Abstammung kaum und dann oft in negativen Stereotypen repräsentiert werden, unterlag auch die Darstellung der afroamerikanischen Bevölkerungsgruppe stets negativen Klischees. ${ }^{39}$ Dies gilt auch für Bevölkerungsgruppen wie Homosexuelle und stellt eine Entwicklung dar, die sich vielleicht abgeflacht, aber sicherlich noch kein Ende gefunden hat.

Um diese Beobachtungen zu bündeln, liegt erneut eine Anwendung des Semiosphärenmodells nahe (vgl. 1.1.3).

Die mediale Familiendarstellung kann als Semiosphäre und die serielle Familiendarstellung als einer ihrer Teilbereiche verstanden werden. Als Zentrum der Semiosphäre bildete sich das mythisierte Ideal der patriarchalen Kernfamilie heraus (vgl. Abb. 2.1). Eine Auflösung dieses Mythos bzw. Umbildung des Zentrums fand nur scheinbar statt. Tatsächlich werden bestimmte Werte, die den Erhalt der (genetischen Kern-)Familie zum Dogma erheben, bereits seit Längerem nur mehr perpetuiert und durch die Ereignisfolge, d. h. die Konsequenzen des Figurenhandelns, vermittelt und nicht intradiegetisch diskutiert und ergründet: „Diskussion ist ebenso wie theoretische Didaktik der Vermittlung von Werten nicht möglich. In Familienserien ,lernt" man durch das Leben“" (vgl. Decker et al. 1996: 80 f.). Eine tatsächliche Veränderung im innersten Kern der Semiosphäre fand also nicht statt, es wurde weiterhin viel des Gleichen in das Zentrum integriert,

Modelle im frühen Alter zeigt, dass diese - werden sie auch im Erwachsenen-Programm zunehmend aufgelöst - weiterhin als das gelten, was Kindern als Norm vermittelt werden soll. Alles andere gilt dementsprechend weiterhin als abweichend, als nicht normal und nicht ideal.

${ }^{38}$ Die HBO-Serie The Divorce (2016-2019) fokussiert beispielsweise die Scheidung eines Ehepaares und die anschließende Suche nach neuen Strukturen.

${ }^{39}$ Dies ist besonders problematisch, wenn man in Betracht zieht, dass im Jahr 2018 fast $40 \%$ der Menschen mit US-amerikanischer Staatsbürgerschaft einer Minderheit angehörten. Dabei lag der Anteil von Menschen hispanischer Abstammung bei 18,3\% und der von Menschen afroamerikanischer Abstammung bei 13,39\% (vgl. Statista 2018). 


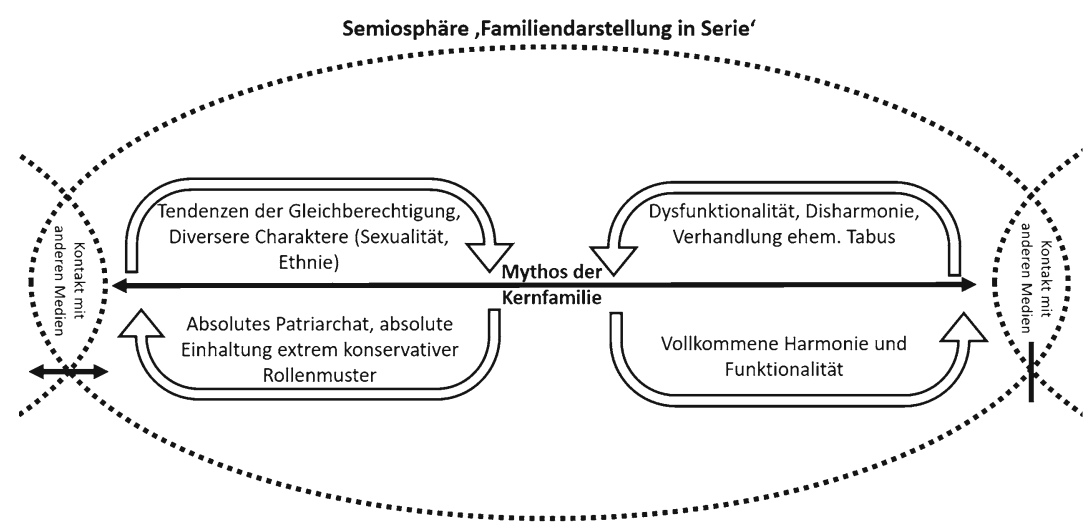

Abb. 2.1 Semiosphäre ,Familiendarstellung in Serie“

das sich damit festigte. Die scheinbare Änderung des Zentrums besteht in der Integration bestimmter Elemente z. B. vermehrter Gleichberechtigung, Darstellung homosexueller Figuren und Figuren diverser Ethnien. Ebenso wurden familiäre Disharmonie, Dysfunktionalität und die offene Verhandlung ehedem tabuisierter Thematiken ins Zentrum integriert. Eine Desintegration fand bezüglich absolut patriarchaler Strukturen, der unbedingten Bindung an extrem konservative Rollenmuster (z. B. „Frauen dürfen nicht Arbeiten und sind an Heim und Herd gekettet“") und vollkommener Harmonie statt.

Aus diesen Integrationsprozessen und der gleichzeitigen Stabilität des Kerns, der in seiner inneren Struktur nicht angetastet wurde, ergibt sich ein Widerspruch, der spätestens seit der neueren Zeichentricksitcom deutlich hervortritt. Die Mythen des Kerns erscheinen durch die sie umgebende Dysfunktionalität und Disharmonie und die Präsenz alternativer Lebensmodelle als hohles Dogma (vgl. Kelsch 2019: 151 f.). Das Zentrum der Semiosphäre ,Familiendarstellung in Serie" steht also im Konflikt mit der äußeren und inneren Peripherie, gleich - bildlich gesprochen - des harten Kernes einer weichen Frucht. Inwieweit sich dieses Zentrum der Semiosphäre in neuesten Medienprodukten einer Veränderung unterzieht, soll am Beispiel der Video-on-Demand-Serie überprüft werden. Um die entsprechende Entwicklung nachvollziehen zu können, wird das Modell unter 4. erneut aufgegriffen. 


\section{8 "It's not TV - It's Netflix“: Antizipation der Rolle der Video-on-Demand-Anbieter}

Knüpfen die Video-on-Demand-Serien als repräsentative Beispiele für die aktuelle Serienlandschaft an die dekonstruktiven Tendenzen der Zeichentricksitcom an oder greifen sie auf vorherige Strukturen zurück? Dies wird die zentrale Frage meiner späteren Analyse sein. In diesem Abschnitt soll es, weitgehend unabhängig von der Familienthematik, darum gehen, die generellen Möglichkeiten der Streaming-Dienste bezüglich der narrativen Gestaltung der Formate zu diskutieren und dementsprechend potenzielle künftige Entwicklungen zu skizzieren.

Um den Aufstieg der Streaming-Dienste mit Beginn der 2010er Jahre nachvollziehen zu können, ist ein Blick auf den Anfang dieses Jahrtausends notwendig: Mit dem Jahr 1999 wurde, nach der Etablierung des Fernsehens in den 1950er Jahren und der Diversifizierung des Programms durch den Aufstieg der Kabelsender in den 1980er Jahren, das ,third golden age of television“ eingeleitet. ${ }^{40}$ Vor allem der Bezahlfernsehsender HBO kann mit Serien wie The Sopranos oder The Wire (2002-2008) als Wegbereiter dieses ,Zeitalters' gelten (vgl. Fröhlich 2015: 457, vgl. Schleich/Nesselhauf 2016: 45, vgl. Kupper 2016: 18 f.). ${ }^{41}$ Mit dem Aufkommen der DVDs waren die Abonnementzahlen des Senders zunehmend gesunken, da das zentrale Verkaufsargument die Ausstrahlung von Kinofilmen vor ihrem Erscheinen im „basic cable“, also dem nicht gesondert kostenpflichtigen Kabelfernsehen, gewesen war. Als Reaktion begann der Sender exklusive, hochwertige Inhalte zu generieren, die zu einem erfolgreichen Alleinstellungsmerkmal und Abonnementgrund wurden (vgl. Schleich/Nesselhauf 2016: $44 \mathrm{f}$., vgl. Fröhlich 2015: 457 f.).

Serien von Sendern wie HBO haben dabei eine Vielzahl an Besonderheiten gegenüber dem restlichen US-Fernsehen: Durch das Abonnementmodell

\footnotetext{
${ }^{40}$ Angesichts der Tatsache, dass es somit innerhalb von 50 bis 60 Jahren drei, goldene Zeitalter' des Fernsehens gegeben haben soll, ist diese Betitelung etwas fragwürdig und irreführend. Durch die Betitelung als Zeitalter wird zum einen der Eindruck einer disjunkten Trennung zwischen den Jahrzehnten erweckt, zum anderen scheint es, als ob in den Jahrzehnten zwischen den , goldenen Zeitaltern ' das Fernsehen bedeutend an Popularität oder Inhalt verloren hätte. Aus aktueller Perspektive wäre es sinnvoller, den Aufstieg des Fernsehens seit den 1950er Jahren bis zur erwachenden Konkurrenz durch Video-on-Demand-Anbieter als das ,golden age of television“ bzw. den Siegeszug des Fernsehens und die herausstechenden Aspekte nur als Wegmarken zu betrachten.

${ }^{41}$ In Deutschland bildeten die Bezahl-Fernsehsender Premiere und seit 2009 dessen Nachfolger Sky den Vorläufer des Video-on-Demand. Sky nimmt u. a. durch die Ausstrahlung von Inhalten von Warner Media, darunter populäre HBO-Serien wie Game of Thrones, einen relevanten Platz im deutschen Streaming-Markt ein.
} 
unterliegen sie nicht der Zensur bzw. den Einschränkungen, denen das restliche US-Fernsehen unterliegt. Dementsprechend können die Eigenproduktionen Gewalt, Nacktheit und Schimpfwörter beinhalten, ohne Sanktionen befürchten zu müssen (vgl. Fröhlich 2015: 458, vgl. Schleich/Nesselhauf 2016: 44.). ${ }^{42}$

Ein weiterer Faktor ist, dass verpasste Folgen häufig nachgeholt werden können, sei es auf Online-Portalen oder im Zuge von häufigen Wiederholungen. Zudem ist das Programm frei von Werbung, wodurch keine Ausrichtung der Erzählstruktur an Unterbrechungen mehr notwendig ist (vgl. Fröhlich 2015: 458 f., vgl. Schleich/Nesselhauf 2016: 45). Vor allem aber sind Pay-TV-Sender nicht von kurzfristigen Einschaltquoten, sondern von den Abonnementgebühren und den Verkaufszahlen der Datenträger abhängig. Die Zuschauenden sind bereit, für das „Gesamtpaket HBO“ (Fröhlich 2015: 460) zu zahlen, somit ist für den Sender das Image als Produzent hochwertiger und anspruchsvoller Unterhaltung von Bedeutung (vgl. Fröhlich 2015: 460). Im Vergleich zu früheren TV-Produktionen verändert sich obendrein die Art und Weise, wie erzählt wird: „Ein längerer Erzählatmen kann eingeplant werden, da sie nicht sofort zu einem plot point oder einer Klimax kommen müssen“ (Fröhlich 2015: 459, vgl. Schleich/Nesselhauf 2016: 45). ${ }^{43}$

Durch die genannten Faktoren und indem sie bewusst den Eindruck eines filmischen Charakters stärken, vermitteln diese Serien den Eindruck der Andersartigkeit und der Hochwertigkeit gegenüber dem , normalen“ Programm. Es soll vermittelt werden, dass es sich nicht um bloße Massenproduktion, sondern um eine Art „Autorenserie“ handelt, die - wie ein Roman - in den Händen einer Regisseurin bzw. eines Regisseurs oder ,creators“ zusammenläuft (vgl. Fröhlich 2015: 460 f., vgl. Kupper 2016: 20 f.). Dem Pay-TV gelang es somit erfolgreich, Maßstäbe zu setzen, was die folgende Serienproduktion anging:

Nur bei Bezahlfernsehsendern - so lautet die Werbebotschaft - bekommen die Kunden werbefrei, ungeschnittene, an Erwachsene gerichtete, exklusive, qualitätsvoll,filmische“ Produkte, die es nirgendwo im ,kostenlosen' network-Fernsehen zu sehen

\footnotetext{
42 Dies zeigt sich beispielhaft in überaus populären Formaten wie Game of Thrones (20112019; HBO), Breaking Bad (2008-2013; AMC), The Walking Dead (seit 2010; AMC) oder Preacher (2016-2019; AMC). Besonders The Walking Dead und Preacher neigen zu einer hyperbolischen Darstellung von Gewalt.

${ }^{43}$ Eine Entwicklung hin zu komplexeren Narrationen wurde durch die erhöhte Popularität bzw. Verfügbarkeit von DVDs seit Beginn der 2000er begünstigt - man konnte erstmals gesamte Staffeln in einem kompakten Format erwerben - ebenso wie durch die Möglichkeit zum Download von Inhalten (vgl. Blanchet 2011: 40 f., vgl. auch Schleich/Nesselhauf 2016: 209).
} 
gibt. Der viel zitierte Slogan HBOs von 1996 bis 2009 „It's not TV. It's HBO“ brachte diesen Anspruch und die Corporate Identity auf den Punkt. (Fröhlich 2015: 462)

So bezeichnete auch der Medienwissenschaftler Al Auster HBO 2005 als „the standard of quality in contemporary American television“ (Auster 2005: 227). Entsprechend prägte sich für die Serien der - wie unter 1 schon angemerkt problematische Begriff der "Quality Television Series“ (vgl. Köhler 2011: 15, vgl. Rothemund 2013: 24 f.), der die darunter gefassten Formate auf- und den Rest des Fernsehens sowie alle vorangehenden Formate abwertet. Der langjährige HBO-Slogan „It's not TV. It's HBO“ unterstützte diesen Exklusivitätseindruck der pejorativen Abhebung vom Fernsehen. Auch die journalistische Kritik tat ihr Übriges, um den Eindruck einer nie gekannten Qualität der TV-Serien hervorzuheben:

Der Tenor ist, dass innovatives, anspruchsvolles Erzählen mit gesellschaftlicher und gesellschaftspolitischer Relevanz heute weniger in der Literatur und im abendfüllenden Film, sondern im Gewand filmischer Serialität zu finden ist. (Milevski et al. 2018: 14)

Trotz der Problematik des Begriffs "Quality-TV“ ist der besondere Stellenwert, den die Serie durch diese ,Aufwertung ' erhalten hat, nicht zu unterschätzen, da sie die enorme Popularität der Eigenproduktionen der Streaming-Anbieter überhaupt erst ermöglichte. Hatte die Serie, wie Hickethier schreibt, in den 1990er Jahren ihre Legitimation „durch die massenmediale Praxis erhalten“ (vgl. Hickethier 1991: 7), so hat sie mit Hilfe der Pay-TV-Sender die Stufen zum Thron medialer Darstellungsformen erklommen und sich - durch die Streaming-Dienste - scheinbar unverrückbar auf diesem niedergelassen.

Die Streaming-Dienste, für die der Anbieter Netflix exemplarisch steht, folgten einer ähnlichen Strategie wie das Pay-TV. Der 1997 als rasch erfolgreicher DVD-Verleih bzw. -Versand gegründete Konzern (vgl. McDonald/Smith-Rowsey 2016: 1) eröffnete 2007 sein Online-Angebot, dessen Abonnementzahl die des DVD-Verleihs bereits 2012 überstieg (vgl. McDonald/Smith-Rowsey 2016: 7). Mit Lilyhammer produzierte der Anbieter 2012, in Kooperation mit dem norwegischen Sender NRK1, schließlich das erste „Original“, dem bald eine Vielzahl weiterer Serien und Filme folgte. ${ }^{44}$ Seit der Etablierung des Video-on-DemandDienstes konnte Netflix enorme Erfolge verzeichnen: Der Dienst ist - laut eigenen Angaben - in über 190 Ländern der Erde zugänglich (vgl. Netflix.com 2019) und

\footnotetext{
${ }^{44}$ Mehr zur Geschichte und Entwicklung Netflix ‘ in der Einleitung zu The Netflix Effect herausgegeben von Kevin McDonald und Daniel Smith-Rowsey (vgl. McDonald/Smith-Rowsey 2016: 1-11).
} 
die Zahl der Abonnierenden erreichte im zweiten Quartal 2019 über 157 Millionen (vgl. Statista 2019 I). Aufgrund der verbreiteten Praxis des Teilens von Zugangsdaten liegt die tatsächliche Zahl der Nutzenden wohl deutlich höher. ${ }^{45}$ Zudem ist in Zukunft ein deutlicher Anstieg an Streaming-Diensten zu erwarten, wie unter anderem Disney + (vgl. Sorrentino/Solsman 2019) oder das geplante Streaming-Angebot von Warner Bros. (vgl. Sarsky 2019), während das herkömmliche Fernsehen sich vermehrt an Taktiken der Anbieter orientiert und beispielsweise Serien in Online-Mediatheken - teilweise vor der Ausstrahlung im TV - zur Verfügung stellt (vgl. Schleich/Nesselhauf 2016: 212).

\subsubsection{Auswahl und Genrezuweisung}

Worin begründet sich nun der Erfolg des sogenannten ,nicht-linearen Fernsehens“ (vgl. Schleich/Nesselhauf 2016: 208)? Dieser ist auf verschiedene Faktoren zurückzuführen. Zwar müssen Nutzende auf alle Arten von Formaten verzichten, die auf eine Live- oder zeitnahe Ausstrahlung angewiesen sind, dahingegen profitieren sie von einem Katalog mit nutzungsfreundlicher Oberfläche, den sie anhand personalisierter Empfehlungen und ohne Werbeunterbrechungen erforschen können (vgl. Arnold 2016: 51). Obwohl die Auswahl groß ist, ist der Katalog natürlich endlich und enthält nicht ansatzweise alle populären Serien oder Filme. Das User Interface von Netflix etwa ist darauf ausgelegt, einen gegenteiligen Eindruck der unendlichen Auswahl zu erwecken, und lenkt dabei davon ab, dass sich die Auswahl - aufgrund abgelaufener und neuer Lizenzen - im stetigen Wandel befindet (vgl. Alexander 2016: 86). Die vorhandenen Inhalte sind zudem in eine Vielzahl von Genres und Subgenres gegliedert. So finden sich beispielsweise im Juli 2019 unter dem Film-Genre „Romantisch“ auf der deutschen Netflix-Webseite die Subgenres „Romantische Komödien“, „Alberne Komödien“, „Independent-Komödien“ und unter dem Serien-Genre „Horror“ die Subgenres „Düstere Thrillerserien“, „Übernatürliche Thrillerserien“ sowie „Internationale Thriller- und Mysteryserien“. Die indische Serie Ghul (2018) findet sich dabei in allen drei der letztgenannten Kategorien wieder. Die zahlreichen Zuschreibungen und Unterteilungen unterliegen nicht der Kontrolle der Nutzenden, weisen zahlreiche Doppelzuweisungen und Überschneidungen auf und sind

${ }^{45}$ Die Zahl der Nutzenden des größten Netflix-Konkurrenten Prime Video des OnlineVersandhändlers Amazon ist durch die Kopplung des Angebots an das „Amazon Prime“Modell schwer zu ermitteln. 
dementsprechend undurchschaubar (vgl. Smith-Rowsey 2016: 67). ${ }^{46}$ Gerade aus diesem Grund tragen sie dazu bei, das Angebot als extrem umfassend darzustellen. Dies in Verbindung mit der Wandlung des Kataloges (Formate verschwinden und kommen hinzu) führt dazu, dass die Nutzenden stets das Gefühl haben, Neues entdecken zu können, und somit dem Anbieter verhaftet bleiben.

\subsubsection{Personalisierung?}

Tatsächlich entzieht sich auch die Anordnung und Organisation der persönlichen Bibliothek weitestgehend der Kontrolle der Nutzenden. Beim Öffnen der Webseite wird man zunächst mit prominent platzierten Vorschlägen konfrontiert, die sofort - ohne Zutun der Nutzerin oder des Nutzers - als Trailer abgespielt werden; hat man die App auf dem Handy installiert, erhält man zudem regelmäßig Benachrichtigungen wie „Suggestion for Jakob - We think you'll like Dracula“. Der Eindruck, das Konto sei in höchstem Maße personalisiert, wird offensiv vermittelt, wodurch der Eindruck eines allgemein personalisierten Angebots entsteht. Die vermeintliche Rolle der Nutzenden als „Programmdirektoren“ (Milevski et al. 2018: 15) ist kritisch zu betrachten. Natürlich hat Netflix Zugriff auf einen umfangreichen Datenschatz, der Aufschluss über die Vorlieben der Nutzenden gibt, und kann diesen bei der Entscheidung, ob Formate produziert werden sollen oder nicht, heranziehen (vgl. Madrigal 2014). Dennoch steht die Frage im Raum, inwiefern die Nutzenden hier prägend sind oder Netflix deren Vorlieben prägt. Der Personalisierungsprozess unterliegt - abgesehen von einer sehr vagen Angabe der Vorlieben bei Generierung eines Profils - nicht der Kontrolle der Nutzenden, sondern verläuft automatisiert auf Basis der Rezeptionsgewohnheiten (vgl. Arnold 2016: 56). Je mehr nun rezipiert, je größer die Datenmenge wird, die Netflix zur Verfügung steht, desto kleiner wird - scheinbar paradoxerweise - die Varianz der Empfehlungen, desto geringer ist die Chance, mit einem Film oder einer Serie

\footnotetext{
${ }^{46}$ Ein weiteres Beispiel für die Undurchschaubarkeit der Kategorisierung: Die Webseite der britischen Tageszeitung ,The Mirror“ listet in einem Beitrag vom 07.10.2019 die Links zu 199 Kategorien auf (vgl. Knight 2019). Diese sind dann auf Netflix erneut in verschiedene Kategorien unterteilt. Sucht man beispielsweise nach „Crime TV Shows“, ist die Liste unterteilt in „Netflix Originals“, „,Trending Now“, ,TV Comedies“, „Popular on Netflix“, ,New Releases“, „Critically Acclaimed Bingeworthy TV Shows“, „Bingeworthy TV Thrillers“, „Dark Suspenseful TV Shows“, „US TV Shows“, „,TV Dramas“, „Get In On Action“, „European Movies \& TV“, ,Crime TV Dramas“, „Documentaries“, ,,Relentless Crime Dramas“, „German TV Shows“, „Slow Burn“, „TV Shows“ sowie 15 weitere Kategorien, einer Top-Auswahl der Filme für das jeweilige Konto sowie diverse Empfehlungen, weil bestimmte andere Serien und Filme der Kategorie gesehen wurden (Stand 31.03.2020).
} 
außerhalb der persönlichen Komfortzone konfrontiert zu werden (vgl. Alexander 2016: 89). ${ }^{47}$ Es findet also, wie Sarah Arnold es benennt, eine „Ghettoisierung“ der Nutzenden statt (vgl. Arnold 2016: 56). Eine - für das Phänomen der Personalisierung charakteristische - „Filterblase“ bildet sich (vgl. Pariser 2012: 16). ${ }^{48}$ Sollte der Nutzer nicht bewusst die Bequemlichkeit der Empfehlungen verlassen, wird sich diese Blase nicht mehr entwickeln, sondern lediglich - auf Basis einer in sich konstanten Datenmenge - stagnieren (vgl. Grunwald 2018: 43). Durch diesen Prozess kann es sein, dass man nicht mehr mit Formaten konfrontiert wird, die dem eigenen Geschmack zwar algorithmisch entgegenlaufen, ihm aber in der Realität entsprechen oder ihn bereichern könnten (vgl. Alexander 2016: 94). Diese ,Wand aus Empfehlungen“ zu durchbrechen, verlangt den Aufwand eines bewussten Stöberns und Suchens - ein Prozess, der mit einem gewissen Aufwand verbunden ist. Sollte man sich normalerweise nicht für ostasiatische Filme und Serie interessieren, wird man kaum auf das durchaus große Angebot an z. B. koreanischen Formaten auf Netflix stoßen.

Der Eindruck, Netflix würde die absolut freie Wahl begünstigen, ist also ein Trugschluss:

Although Netflix's brand identity centers on notions of user choice, its algorithms work to actively negate choice. Human agency is infringed on through the discreet operations of the PRS [personalization and recommendations system, Anm. des Verfassers], which masks its own operations. The user's ability to act, to determine among the totality of the Netflix service and without reference to their profile, is impeded. The PRS commandeers choice so that the user will not experience the burden of selfdefinition and autonomy. Netflix acts so that the user does not have to. Human agency,

${ }^{47}$ Für eine ausführliche Darlegung der (mathematischen) Funktionsweisen des NetflixAlgorithmus vgl. Alexander 2016: $88 \mathrm{ff}$.

${ }^{48}$ Filterblasen entstehen nach Seth Flaxman u. a. durch die Personalisierung, welche beispielsweise Suchmaschinen und soziale Netzwerke anhand des Verhaltens der Nutzenden vornehmen. Somit werden Räume aufgebaut, ,in which algorithms inadvertently amplify ideological segregation by automatically recommending content an individual is likely to agree with“ (Flaxman u. a. 2016: 299). Scheint ein solches Phänomen zwar nahezuliegen, bestehen doch gerechtfertigte Einwände: Zum einen wird auf die komplexe wissenschaftliche Fassbarkeit des Phänomens hingewiesen, zum anderen darauf, dass Menschen unter anderem durch die digitale Vernetzung mit Andersdenkenden, durchaus im Internet Diskursen ausgesetzt sind, die ihren eigenen Überzeugungen entgegenlaufen und dementsprechend eine Änderung ihrer Einstellung bewirken könnten. Soziale Netzwerke, so wird des Weiteren argumentiert, könnten zwar auf der Basis ihrer technisch-apparativen Grundlagen durchaus eine Segregation begünstigen, letztlich sei es jedoch Sache des Individuums, sich für den Konsum nur einer Art von Nachrichten zu entscheiden bzw. sich mit Standpunkten auseinanderzusetzen, die von den eigenen abweichen (vgl. Bakshy et al. 2015: 1132, vgl. auch Flaxman et al. 2016: 317). 
here, is posited as an encumbrance, something best surrendered so that the user is not overwhelmed with uncertainty and, in the worst case, indecision. In exchange for the convenient service offered by Netflix through its PRS, the user forgoes the labor required by autonomous action and independent choice and unwittingly submits to another form of less burdensome labor: that of being subjected to an ongoing process of data monitoring. (Arnold 2016: 59)

Entsprechend stellt sich die Frage, ob sich die Programme von StreamingAnbietern den tatsächlichen Präferenzen der Nutzenden anpassen oder ob vielmehr eine - intendierte oder nicht intendierte - Manipulation in Richtung bestimmter Kategorien vorliegt. In Bezug auf Personalisierung liegt spontan die Vermutung nahe, Streaming-Dienste würden zu einer Ausweitung und Diversifizierung des Serienangebotes beitragen, zu einer wachsenden Zahl des Serienangebotes jenseits des Mainstreams. In Anbetracht obiger Argumentation ist hierbei allerdings die Frage in Betracht zu ziehen, ob sich nicht eher die Vorlieben der Rezipierenden dem Angebot anpassen und somit ein neuer Mainstream etabliert wird. Dies kann hier zwar nicht abschließend beantwortet werden, liegt aber angesichts der wirtschaftlichen Orientierung der Anbieter nahe: „If they are moving toward neoliberalism, under the very regime that nurtures the digital era's trajectories, it would be ironic to understand Netflix or it's users as ,gamechangers ““ (Sim 2016: 197).

\subsubsection{Binge-Watching und dessen Auswirkungen auf die Narration}

Im Bereich der Rezeptionsgewohnheiten ergeben sich durch die StreamingAnbieter tatsächliche Änderungen. Laut Casey McCormick wurde das „BingeWatching“ - von „to binge“ nach pons.com zu Deutsch „heißhungrig essen“, ,sich mit etwas vollstopfen" -, das mit der Verfügbarkeit von Serien auf VHS und DVD aufkam (vgl. McCormick 2016: 102), durch Video-on-Demand-Angebote zum dominanten Modus des Fernsehkonsums (vgl. McCormick 2016: 101). Der Konsum vieler Serienfolgen am Stück wird durch die Ausstrahlungskultur der Dienste ermöglicht bzw. begünstigt. Serien werden nur noch selten mit einer Folge pro Woche veröffentlicht, sondern erscheinen als gesamte Staffel, die dann sofort und ohne Pause rezipiert werden kann.

Aufgrund des Binge-Watching kann zudem auf Zusammenfassungen des bisherigen Inhalts und erzwungene Cliffhanger verzichtet werden (vgl. McCormick 2016: 102). Am Beispiel von House of Cards, einem Politdrama um den Aufstieg des Abgeordneten Frank Underwood zum Präsidenten der USA, vollzieht 
McCormick die Eigenheiten des Binge-Watching nach. Zunächst sei die Serie, in Ermangelung von Rückblenden und Wiederholungen, stark vorwärtsgewandt (vgl. McCormick 2016: 104) und nicht in Folgen, sondern in über die Staffeln fortlaufende Kapitel (1 bis 73) aufgeteilt. Damit wird der Eindruck eines zusammenhängenden Werkes mit Buchcharakter betont und die Serie somit auf eine literarische Ebene gehoben. Es entsteht das Gefühl, eher einen zusammenhängenden Film als ein serielles Format rezipiert zu haben (vgl. McCormick 2016: 105). Die bewusste Abgrenzung zu ,gewöhnlichen' Serien ist identisch mit der Abgrenzungsstrategie des Quality-TV.

Bereits durch die Serien des Quality-TV zeichnete sich eine zunehmende Tendenz zu längeren Handlungsverläufen ab, weg von der Episoden hin zur Fortsetzungsserie ab (vgl. Kupper 2016: 25). Durch das Binge-Watching verlieren Einzelfolgen und somit gewissermaßen die serielle Narration insgesamt - im Sinne einer episodischen Erzählung - an Eigenwert. Die Episodenstruktur, d. h. klar erkennbare Einheiten, nannte Hickethier 1991 noch als grundlegendes Merkmal der Serie (vgl. Hickethier 1991: 9). Auch die (zeitliche) „Einbindung in einen Programmzusammenhang“, wie sie lange Zeit als konstitutiv für die audiovisuelle Serie galt (vgl. Hickethier 1994: 58), hat - zugunsten programmunabhängiger Rezeption - heute nahezu vollkommen an Bedeutung verloren. Im Unterschied zur TV-Ausstrahlung, bei der die Serie nicht jederzeit in vollem Umfang abrufbar ist, muss auch nicht jede Episode einen einfachen Einstieg in die Handlung ermöglichen (vgl. Blanchet 2011: 40 f.). Theoretisch könnten somit repetitive und erklärende Momente ausgespart werden. ${ }^{49}$

McCormick argumentiert, die neue Form der Rezeption trüge entscheidend dazu bei, narrativ komplexe Serien nachvollziehen und genießen zu können (vgl. McCormick 2016: 101). Letztendlich bleibt zu diskutieren, ob dies der Fall ist. Gegenläufig ließe sich anbringen, dass die Zeit zwischen den Episoden bei einer konventionellen Ausstrahlung die Möglichkeit lässt, das Gesehene zu reflektieren und zu überdenken, und somit sogar eine tiefergehende gedankliche Einbindung zulässt. Zudem setzt man sich durch den sukzessiven Konsum über einen längeren Zeitraum mit der Serie auseinander, das Rezipieren einer

\footnotetext{
${ }^{49}$ Zudem können die Episoden der Serien - da sie nicht mehr fest in das TV-Programm eingebunden sind - in ihrer Länge variieren. Theoretisch kann sich somit die Länge der Episode am Inhalt ausrichten und muss nicht - wie zuvor - exakt 30 oder 45 Minuten lang sein. Dies ist bereits der Fall: So sind die Episoden der ersten Staffel des Netflix Originals Ozark zwischen ca. 52 und 80 Minuten (Staffelfinale) lang. Allgemein bleiben die Schwankungen allerdings im Bereich einiger Minuten und Serienfolgen orientieren sich - wie zuvor - an einer Länge von tendenziell einer vollen oder einer halben Stunde, mit Ausnahme weniger Episoden mit Überlänge.
} 
Serie wird mehr ,zelebriert". Dahingehend lässt das Bild vom ,Verschlingen“ an unreflektierten Konsum denken und widerspricht der ohnehin vagen Komplexitätsbehauptung. Dass auf Handlungszusammenfassungen verzichtet wird, eine Narration langsamer erfolgt und den Einzelcharakteren mehr Erzählzeit zugestanden wird, bedeutet nicht unbedingt, dass die Serie komplexer in dem Sinne ist, dass sie schwerer zugänglich oder verständlich ist. Es handelt sich lediglich um eine - an die Art der Distribution angepasste - Veränderung der Erzählstruktur. Bei genauerer Betrachtung erscheint der vage Komplexitätsbegriff ebenso pejorativ wie der des Quality-TV. Ist es nicht gerade das Binge-Watching, das Serien zu einem austauschbaren Massengut macht? Schließlich geht es mit einer nie gekannten Popularität der Formate einher und kann durchaus auch als wirtschaftliche Strategie betrachtet werden, durch die der Serienkonsum für Rezipierende so alltäglich wird, dass sie den Streaming-Anbietern - allein aus Gewohnheit - als zahlende Kunden treu bleiben. Welche Entwicklungen diesbezüglich stattfinden, bleibt weiter zu beobachten.

Ungeachtet dieser Debatte lässt sich feststellen, dass beispielsweise im Bereich der Zeichentricksitcom eine klare Entwicklung hin zu folgenübergreifenden Handlungssträngen nachzuvollziehen ist (vgl. Kelsch 2019: 112 ff.). Dies ist umso bemerkenswerter, da es sich hier um eine Art von Serie handelt, bei der über lange Zeit die Handlungen einer Episode in der folgenden vollkommen redundant waren. Auch im Falle sämtlicher im Rahmen dieser Untersuchung analysierten Serien liegt - selbst bei starken episodischen Tendenzen in manchen Fällen stets eine klare übergeordnete Handlung vor. Dies ist ebenso bei Serien wie Red Oaks, Grace and Frankie oder The Ranch der Fall, welche man im herkömmlichen Sinne als Sitcom verstehen könnte. Obwohl an dieser Stelle noch kein finales Urteil gefällt werden kann, findet augenscheinlich eine Entwicklung von der Episodenserie hin zur Fortsetzungsserie statt.

\subsubsection{Resümee: Aufstieg oder Fall der Streaming-Dienste?}

Streaming-Dienste ersetzen heute zumindest partiell bereits das konventionelle Fernsehen. Durch die ungemeine Popularität der Eigenproduktionen, den gebotenen Komfort und die zumindest suggerierte Personalisierung sowie durch geschicktes Marketing, das besondere Qualität und Exklusivität verspricht, scheint ihre Stellung gefestigt. Besonders in der jüngeren, westlichen Gesellschaft haben Serien und deren Konsum über Streaming-Anbieter einen Popularitätsgrad erreicht, der diejenigen, die nicht zum Kreis der Rezipierenden gehört, gewissermaßen zu kulturellen Außenseitern macht. Auch der Einfluss der neuen 
Rezeptionskultur (Binge-Watching) auf die formale Gestaltung der Serien kann nicht geleugnet werden, auch wenn weitere Entwicklungen hier abzuwarten bleiben.

Trotz der unleugbaren Erfolge ist die aktuelle Situation unter den StreamingAnbietern problematisch. Die bisherige Monopolisierung zwischen Netflix und Prime Video sowie einigen sekundären und nationalen Anbietern, welche den Nutzenden die Auswahl der Anbieter erleichterte, trug sicherlich mit zum Erfolg der Anbieter bei. Die Konsequenzen der aktuellen Erweiterung des Angebotes an eigenständigen Streaming-Diensten sind nicht abzusehen. Die Eröffnung von Disney + sorgt beispielsweise dafür, dass über kurz oder lang weder die populären Marvel-Formate noch originäre Disney-Produktionen auf Netflix zu sehen sein werden (vgl. Rehfeld 2018). Ebenso dürfte ein Warner Bros.-Angebot eine ernsthafte Konkurrenz darstellen, gehört doch der Sender HBO und damit dessen ungemein populäre Eigenproduktionen wie Game of Thrones dem Konzern an. Nachdem gerade die Zentralisierung der Streaming-Dienste für einen Rückgang des illegalen Medienkonsums gesorgt hat, ist nicht auszuschließen, dass die Dezentralisierung eine gegenteilige Konsequenz haben wird (vgl. Fischer 2019). Aktuell ist bereits ein eskalativer und enorm kostenintensiver ,war for content" entbrannt, ein Konkurrenzkampf zwischen Streaming-Anbietern und großen Medienkonzernen, um die ,besten“ bzw. publikumswirksamsten Inhalte (vgl. Hennig-Thurau et al. 2019: 4 f., 18 f.). Anstatt vier oder fünf monatliche Abonnementgebühren zahlen zu müssen, um eine Serie oder einen Film zu sehen, mag es vielen attraktiver scheinen, auf die zwar deutlich weniger komfortablen und natürlich illegalen, aber dafür kostenfreien Seiten zurückzukehren ${ }^{50}$ oder doch auf eine Ausstrahlung im Fernsehen zu warten. Vielleicht - und diese Möglichkeit steht durchaus im Raum - wird gerade die Konkurrenz unter den Anbietern das Geschäft beleben und neue Wege der Kund/inn/enfreundlichkeit eröffnen. Diese Prognosen sind allerdings rein spekulativ.

Auch die oft getätigte Prognose vom Untergang des konventionellen Fernsehens (vgl. z. B. Rehfeld 2018) ist mit Vorsicht zu genießen. Die privilegierte Stellung des TV als Distributor von Serien und Filmen gehört bereits jetzt der Vergangenheit an. Sollten sich nicht bedeutende strukturelle Änderungen im Programm der Streaming-Anbieter entwickeln, nimmt das TV mit Formaten wie Talk und Game-Shows etc., Nachrichten, Live-Sendungen und nationalen sowie regionalen Serien eine Rolle ein, die das Streaming wahrscheinlich nicht ersetzen

\footnotetext{
${ }^{50}$ Obgleich die Video-on-Demand-Anbieter nach wie vor den Markt dominieren, lässt sich bereits aktuell wieder eine erhöhte Tendenz zu illegalem bzw. bedingt legalem Streaming beobachten (vgl. Heckel 2019).
} 
wird. Dass es zunehmend populärer wird, die entsprechenden Programme online zu rezipieren, würde diese Rolle nicht schmälern. ${ }^{51}$ Dennoch wird das ,lineare Fernsehen ,gewaltige Schritte“ (Hennig-Thurau et al. 2019: 5) unternehmen müssen, um in Zukunft in bestimmten Bereichen der Unterhaltung, z. B. Serien und Filme, konkurrenzfähig und attraktiv zu bleiben (vgl. Hennig-Thurau 2019: 40 - mit Bezug auf deutsche Medienanbieter).

Jenseits dieser interessanten, aber spekulativen Fragen bleibt festzustellen, dass das Streaming auf mehreren Ebenen einen ungemeinen Einfluss auf die Medienkultur ausgeübt hat und weiter ausübt. In welche Richtung sich dieser Einfluss entwickeln wird, ist dabei, wie stets im fluiden medialen Prozess, (noch) unklar. Eigentliches Anliegen der vorliegenden Studie ist nun die Darstellung der Familie in Video-on-Demand-Serien zu untersuchen und darüber Rückschlüsse darauf ziehen zu können, ob Video-on-Demand-Anbieter auf inhaltlicher Ebene einen Wandel bewirken.

Open Access Dieses Kapitel wird unter der Creative Commons Namensnennung 4.0 International Lizenz (http://creativecommons.org/licenses/by/4.0/deed.de) veröffentlicht, welche die Nutzung, Vervielfältigung, Bearbeitung, Verbreitung und Wiedergabe in jeglichem Medium und Format erlaubt, sofern Sie den/die ursprünglichen Autor(en) und die Quelle ordnungsgemäß nennen, einen Link zur Creative Commons Lizenz beifügen und angeben, ob Änderungen vorgenommen wurden.

Die in diesem Kapitel enthaltenen Bilder und sonstiges Drittmaterial unterliegen ebenfalls der genannten Creative Commons Lizenz, sofern sich aus der Abbildungslegende nichts anderes ergibt. Sofern das betreffende Material nicht unter der genannten Creative Commons Lizenz steht und die betreffende Handlung nicht nach gesetzlichen Vorschriften erlaubt ist, ist für die oben aufgeführten Weiterverwendungen des Materials die Einwilligung des jeweiligen Rechteinhabers einzuholen.

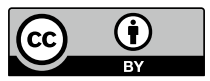

\footnotetext{
${ }^{51}$ So stellt Timo Niemeier mit Verweis auf eine Deloitte-Studie fest, dass die Video-onDemand-Anbieter - aufgrund TV-spezifischer Formate - nur bedingt eine Konkurrenz für das konventionelle Fernsehen seien. Zudem sei der Video-on-Demand-Markt bereits gesättigt und würde kein nennenswertes Wachstum mehr verzeichnen (vgl. Niemeier 2019). Eine Studie von Hennig-Thurau et al. ergibt hingegen, dass ,TV-Anbieter deutlich mehr tun müssen als bisher“, um nicht als „Digitalisierungsopfer“ zu enden wie die „Videothekenkette Blockbuster" (Hennig-Thurau et al. 2019: 5). Zur Entwicklung der deutschen Medienlandschaft in Zeiten der Digitalisierung möchte ich dementsprechend verweisen auf Hennig-Thurau et al. 2019.
} 